\title{
Influence of glass polymerisation and oxidation on micro-Raman water analysis in alumino-silicate glasses
}

\author{
Maxime Mercier $^{\mathrm{a},}$ Andrea Di Muro ${ }^{\mathrm{ab}}$, Daniele Giordano ${ }^{\mathrm{c}}$, Nicole Métrich ${ }^{\mathrm{a}}$, Priscille \\ Lesne $^{d}$, Michel Pichavant ${ }^{d}$, Bruno Scaillet ${ }^{d}$, Roberto Clocchiatti ${ }^{\mathrm{a}}$ and Gilles Montagnac ${ }^{\mathrm{e}}$ \\ ${ }^{\mathrm{a}}$ Laboratoire Pierre Süe, CNRS-CEA, CE-Saclay, 91191 Gif sur Yvette, France \\ ${ }^{\mathrm{b}}$ Laboratoire PMMP, Université Paris VI, 4 Place Jussieu, 75005 Paris, France \\ ${ }^{\mathrm{c}}$ Dipartimento di Scienze Geologiche, Università di Roma Tre, Largo Leonardo Murialdo, 1, \\ 00154 Roma, Italy
}

dinstitut des Sciences de la Terre d'Orléans, Université d'Orléans, CNRS-INSU, UMR 6113, 1a rue de la Férollerie, 45071 Orléans, France

${ }^{\mathrm{e} L a b o r a t o i r e ~ d e s ~ S c i e n c e s ~ d e ~ l a ~ T e r r e, ~ C N R S ~ U M R 5570 ~ E c o l e ~ N o r m a l ~ S u p e ́ r i e u r e, ~} 46$ allée d'Italie, 69364 Lyon, France

\begin{abstract}
The development of an accurate analytical procedure for determination of dissolved water in complex alumino-silicate glasses via micro-Raman analysis requires the assessment of the spectra topology dependence on glass composition. We report here a detailed study of the respective influence of bulk composition, iron oxidation state and total water content on the absolute and relative intensities of the main Raman bands related to glass network vibrations (LF: $\sim 490 \mathrm{~cm}^{-1}$; HF: $\left.\sim 960 \mathrm{~cm}^{-1}\right)$ and total water stretching $\left(\mathrm{H}_{2} \mathrm{O}_{\mathrm{T}}: \sim 3550 \mathrm{~cm}^{-1}\right)$ in natural glasses. The evolution of spectra topology was examined in (i) 33 anhydrous glasses produced by the re-melting of natural rock samples, which span a very large range of polymerisation degree (NBO/T from 0.00 to 1.16), (ii) 2 sets of synthetic anhydrous basaltic glasses with variable iron oxidation state $\left(\mathrm{Fe}^{3+} / \mathrm{Fe}_{\mathrm{T}}\right.$ from 0.05 to 0.87 ), and (iii) 6 sets of natural hydrous glasses $\left(\underline{C}_{\mathrm{H} 2 \mathrm{OT}}\right.$ from 0.4 to $\left.7.0 \mathrm{wt} \%\right)$ with $\mathrm{NBO} / \mathrm{T}$ varying from 0.01 to 0.76 .

In the explored domain of water concentration, external calibration procedure based on the $\mathrm{H}_{2} \mathrm{O}_{\mathrm{T}}$ band height is matrix-independent but its accuracy relies on precise control of the focusing depth and beam energy on the sample. Matrix-dependence strongly affects the internal calibrations based on $\mathrm{H}_{2} \mathrm{O}_{\mathrm{T}}$ height scaled to that of LF or HF bands but its effect decreases from acid (low NBO/T, SM) to basic (high NBO/T, SM) glasses. Structural parameters such as NBO/T (non-bridging oxygen per tetrahedron) and SM (sum of structural modifiers) describe the matrix-dependence better than simple compositional parameters (e.g. $\mathrm{SiO}_{2}, \mathrm{Na}_{2} \mathrm{O}+\mathrm{K}_{2} \mathrm{O}$ ). Iron oxidation state has only a minor influence on band topology in basalts and is thus not expected to significantly affect the Raman determinations of water in mafic (e.g. low $\mathrm{SiO}_{2}$, iron-rich) glasses. Modelling the evolution of the relative band height with polymerisation degree allows us to propose a general equation to predict the dissolved water content in natural glasses:
\end{abstract}




$$
C_{\mathrm{H}_{2} \mathrm{O}_{\mathrm{K}}}=\frac{\left(\mathrm{TOT}_{\mathrm{m}}\right) \times\left(\mathrm{I}_{\mathrm{H}} \mathrm{O}_{n}\right)}{k}
$$

where $\underline{C}_{\mathrm{H} 2 \mathrm{OT}}$ is the total water content (in wt $\%$ ) dissolved in glass; $\mathrm{TOT}_{N}$ represents the computed $I_{\mathrm{LF}} / I_{\mathrm{HF}}$ variation as a function of the calculated NBO/T and SM parameters; $\underline{I}_{\mathrm{H} 2 \mathrm{ON}}$ is the $\mathrm{H}_{2} \mathrm{O}$ band height scaled to ratio of the reference bands; $k$ is the linearity spectrometer response on the $\mathrm{H}_{2} \mathrm{O}_{\mathrm{T}}$ band in function of water content. The water concentrations of the reference glasses are reproduced using this equation with a standard deviation of $0.06 \mathrm{wt} \%$. The adopted parameterisation provides a useful tool towards the characterisation of composition dependence of micro-Raman procedures for silicate glasses. We show, based on the widest range of glass compositions so far investigated, that accurate evaluation of dissolved water content is achieved by micro-Raman spectroscopy.

\section{Introduction}

Water, the main volatile constituent of magmatic and volcanic fluids, has a major influence on mantle partial melting (e.g. Litasov and Ohtani, 2007) and properties of natural aluminosilicate melts and glasses. Water dissolved as hydroxyl groups or molecular water in melts and glasses (e.g. Stolper 1982) affects their viscosity (e.g. [Dingwell et al., 1996], [Richet et al., 1996], [Whittington et al., 2000], [Giordano et al., 2004] and [Giordano et al., 2008]), and density (e.g. [Mysen and Virgo, 1980], [Mysen et al., 1980a], [Mysen et al., 1980b], [Persikov et al., 1990] and [Richet et al., 2000]); as well as phase equilibria, solubilities of metals ([Pichavant et al., 2002] and [Linnen, 2005]) and ultimately magma eruptive styles (e.g. [Di Muro et al., 2004] and [Giordano et al., 2008]). As a consequence, the accurate quantification of the amount of water dissolved in natural melts and glasses is the pre-requisite to an appropriate analysis and modelling of magma properties and differentiation processes. The capability of micro-Raman spectroscopy to determine the total amount of water dissolved in natural and synthetic glasses and minerals has been recently demonstrated ([Thomas, 2000], [Arredondo and Rossman, 2002], [Chabiron et al., 2004], [Zajacz et al., 2005], [Behrens et al., 2006], [Di Muro et al., 2006a], [Di Muro et al., 2006b], [Severs et al., 2007] and [Thomas et al., 2008a]). Besides its accuracy, this technique allows the non-destructive analysis of small amounts of material and does not require long sample preparation. However, accurate water analysis in complex natural glasses, using micro-Raman spectroscopy, is still challenging because the composition dependence of analytical procedures is still poorly understood.

Typically, the Raman spectra of a hydrous silicate glass show a broad band at $\sim 3550 \mathrm{~cm}^{-1}$. This band occurs in both infrared (Stolper, 1982) and Raman (Mysen et al., 1997) spectra and represents the convolution of $\mathrm{OH}$ stretching vibration from hydroxyl groups and molecular water ([Stolper, 1982], [Pandya et al., 1992], [Mysen et al., 1997], [Chabiron et al., 2004] and [Di Muro et al., 2006a]). Accurate determination of absolute Raman heights or areas is difficult and therefore Raman bands are conventionally normalised to one of the two main reference bands (LF or HF) of the silicate network. The low-frequency band (LF $\sim 470$ $\left.570 \mathrm{~cm}^{-1}\right)$ is linked to vibration of $\mathrm{T}-\mathrm{O}^{\circ}$ and the high-frequency band $\left(\mathrm{HF} \sim 950-1000 \mathrm{~cm}^{-1}\right)$ to vibration of $\mathrm{T}-\mathrm{O}^{-}$bonds where $\mathrm{T}$ refers to fourfold coordinated cations; $\mathrm{O}^{\circ}$ to bridging oxygens and $\mathrm{O}^{-}$to non-bridging oxygens (e.g. [Wang et al., 1995] and [Mysen, 1999]). The determination of the total water content is based on the measurement of the absolute or normalised heights or areas of the $\mathrm{H}_{2} \mathrm{O}_{\mathrm{T}}$ band at $\sim 3500 \mathrm{~cm}^{-1}$ following external or internal calibration procedures ([Thomas, 2000], [Chabiron et al., 2004], [Zajacz et al., 2005], 
[Behrens et al., 2006], [Di Muro et al., 2006a], [Di Muro et al., 2006b] and [Severs et al., 2007]).

External calibration in which the area $(A)$ or height $(I)$ of the $\mathrm{H}_{2} \mathrm{O}_{\mathrm{T}}$ band is calibrated through the reiterated measurement of at least one hydrous reference glass ([Thomas, 2000] and [Di Muro et al., 2006a]) is the simplest way to determine the water concentration. This method minimises the compositional dependence but can be affected by either instabilities or errors inherent to the analytical conditions ([Behrens et al., 2006] and [Di Muro et al., 2006a]). The composition dependence of external calibrations is still under debate because of possible changes of molar scattering power of $\mathrm{H}_{2} \mathrm{O}_{\mathrm{T}}$ (Raman cross-section) with glass bulk composition ([Thomas, 2000], [Behrens et al., 2006], [Di Muro et al., 2006a] and [Di Muro et al., 2006b]). On the other hand, internal calibration requires successively the scaling of the area $\left(A^{*}\right)$ or height $\left(I^{*}\right)$ of the $\mathrm{H}_{2} \mathrm{O}_{\mathrm{T}}$ band against the LF and HF silicate network bands, and the calibration of the ratios between the bands $\left(\mathrm{H}_{2} \mathrm{O}_{\mathrm{T}} / \mathrm{LF}\right.$ or $\left.\mathrm{H}_{2} \mathrm{O}_{\mathrm{T}} / \mathrm{HF}\right)$ against a set of hydrous reference glasses. This method overcomes the analytical bias, but is potentially compositiondependent because changes in glass structure affect the Raman spectra topology ([McMillan, 1984], [Mysen, 1988], [Mysen, 2007] and [Sharma et al., 1997]). Raman spectra of silica, alumino-silicate and iron-silicate glasses yield information about the covalently bonded, network-forming structural units in terms of $Q^{n}$ species, where $n$ indicates the number of bridging oxygen. The structural effect of the network-modifying or charge balancing cations is indirectly derived from highly localised Raman bands of $Q^{n}$ species in the HF region (e.g. [Bell et al., 1970] and [Bell and Dean, 1972]). Hence, the net effect of bulk composition on the $I_{\mathrm{LF}} / I_{\mathrm{HF}}$ ratio must be understood prior to any water determination using the internal calibration.

It is well known that the relative height of the LF and HF reference bands of the silicate network, decrease as the glass becomes more depolymerised ([Behrens et al., 2006] and [Di Muro et al., 2006b]). A very sharp decrease in the $\mathrm{LF} / \mathrm{HF}$ height ratio $\left(I_{\mathrm{LF}} / I_{\mathrm{HF}}\right)$ is observed when a small amount of network-modifying cations are added to high $\mathrm{SiO}_{2}$-rich natural glass (e.g. rhyolite) and the NBO/T (number of non-bridging oxygen per tetrahedron, Mysen, 1988) value increases from 0 to 0.10 (Di Muro et al., 2006b). In glasses with intermediate compositions $(0.1<\mathrm{NBO} / \mathrm{T}<0.4)$ (e.g. phonolites, trachytes, dacites, andesites) the $I_{\mathrm{LF}} / I_{\mathrm{HF}}$ ratio decreases more smoothly (Di Muro et al., 2006b). In addition, the content of iron and the relative proportion between ferric and ferrous species can also affect the silicate melt properties, its structure and the Raman spectra topology ([Mysen et al., 1980b], [Kushiro, 1982], [Dingwell and Brearley, 1988], [Dingwell et al., 1988], [Lange and Carmichael, 1990], [Wang et al., 1995], [Magnien et al., 2006] and [Di Muro et al., 2008]).

Here, we explore the respective influence of polymerisation, oxidation state and water content on the Raman spectra typology of natural silicate glasses in order to predict the composition dependence of micro-Raman calibration procedures for the accurate water determination. A method for such determinations is here developed for a wide range of glass compositions. $I_{\mathrm{LF}} / I_{\mathrm{HF}}$ ratio and Raman spectra evolution have been systematically studied in (i) a series of natural anhydrous glasses covering the largest range of composition and degree of polymerisation expressed with NBO/T (Mysen, 1988) and SM (structural modifiers, Giordano and Dingwell, 2003), parameters so far investigated; (ii) two sets of iron-rich basaltic glasses with variable $\mathrm{Fe}^{3+} / \mathrm{Fe}_{\mathrm{T}}$ ratios (from 0.05 to 0.85 , Bonnin-Mosbah et al., 2002) and (iii) six series of hydrous glasses covering a compositional range similar to that of the anhydrous glasses. 


\section{Methodology}

\subsection{Sample selection and characterisation}

\subsubsection{Anhydrous glasses}

The first glass series that was investigated is composed of 33 anhydrous glasses, which cover most of the natural compositional range from strongly polymerised silicic glasses (i.e. metaluminous rhyolite) to highly depolymerised alkaline mafic glasses (i.e. tephrite, basanite). The glass compositions and their provenance are reported in Table 1a. All samples were obtained by re-melting natural rock samples at 1 bar and between 1400 and $1600{ }^{\circ} \mathrm{C}$. Most glasses (22) are from Giordano and Dingwell (2003) and Giordano et al. (2006). In order to cover the widest compositional range of geological interest and to build up a very complete data base, we analysed eight additional glasses with variable degrees of polymerisation (NBO/T from 0.00 to 1.16 ; SM from 8.1 to 43.6). These glasses are increasingly depolymerised and include a metaluminous rhyolite from Rattlesnake Tuff, Oregon (Robert et al., 2008) and another one from the New Berry obsidian lava flow in Oregon (University of British Columbia collection), iron-poor phonolites, a latite, an iron-rich phonolite and a tephri-phonolite (Giordano et al., 2007). Moreover, we synthesised two depolymerised basanitic glasses $(\mathrm{NBO} / \mathrm{T}=0.74$ and 0.77$)$. These latter were prepared at ISTO (Orléans, France). Powders of natural scoriae from La Sommata cone (Vulcano, Italy) were fused at $1400{ }^{\circ} \mathrm{C}$ in air within Pt crucibles. In order to ensure the complete fusion of the sample, a melting cycle of $2 \mathrm{~h}$ was performed; then, samples were rapidly quenched in water. The homogeneity of each sample was tested by electron microprobe analysis.

The second series is composed of anhydrous basaltic glasses with variable $\mathrm{Fe}^{3+} / \mathrm{Fe}_{\mathrm{T}}$ ratios, where $\mathrm{Fe}_{\mathrm{T}}=\left(\mathrm{Fe}^{3+}+\mathrm{Fe}^{2+}\right)$. It includes basaltic glasses with $\mathrm{Fe}^{3+} / \mathrm{Fe}_{\mathrm{T}}$ ratio varying from 0.098 to 0.480 (Etna basalts, Et83) and from 0.049 to 0.875 (Stromboli basalts, Str85; Table 1b). These glasses were obtained by melting powdered natural lava samples at 1260 and $1300{ }^{\circ} \mathrm{C}$ under variable $\mathrm{fO}_{2}$ conditions. They were previously studied by X-ray microspectroscopy at the Fe $K$ edge (Bonnin-Mosbah et al., 2002) and micro-Raman spectroscopy (Di Muro et al., 2008).

\subsubsection{Hydrous glasses}

Four new sets of hydrous glasses were added to the two series of alkaline silicic hydrous glasses (iron-poor and iron-rich phonolites) that were previously studied (Di Muro et al., 2006a) and re-analysed in the present work. Their compositions and synthesis conditions are reported in Table 1c. The new series include silicic, highly polymerised glasses ( 3 metaluminous rhyolites from Turkey, Mexico and Italy) and three sets of depolymerised glasses (basalt from Mt Etna, basanite from La Sommata and tephrite from Vesuvius). The water content ranges from 0.5 to $7.0 \mathrm{wt} \%$ in polymerised silicic glasses and from $0.4 \mathrm{wt} \%$ to $5.3 \mathrm{wt} \%$ in mafic glasses. All hydrous glasses were synthesised at low pressure $(0.2-2.1 \mathrm{kbar})$ in order to minimise the pressure effect on the glass structure and to allow comparison with the set of dry glasses synthesised at one atmosphere. For the purpose of this study, we 
synthesised two water-poor basaltic glasses (Etna basalt) with 0.4 and $0.8 \mathrm{wt} \%$ of water content to extend the range of water concentrations available for Etna basalts, which included glasses with 1.27-3.04 wt $\% \mathrm{H}_{2} \mathrm{O}_{\mathrm{T}}$ (Spilliaert et al., 2006) and a water-rich glass (4.95 $\mathrm{wt} \%$ of $\mathrm{H}_{2} \mathrm{O}_{\mathrm{T}}$; Lesne et al., submitted for publication). Seven basanitic glasses (La Sommata, Vulcano) containing from 0.79 to $4.95 \mathrm{wt} \%$ of dissolved water were also synthesised. The synthesis experiments were conducted at ISTO (Orléans, France), using an Internally Heated Pressure Vessel (IPHV). The natural powdered samples from Etna and La Sommata were loaded into $\mathrm{Au} 80-\mathrm{Pd} 20$ capsules, to which adequate amounts of distilled water were added to ensure water-saturated conditions. The experimental charges were held at different pressures from 0.5 to $2.0 \mathrm{kbar}$ and at $1200{ }^{\circ} \mathrm{C}$ for $5 \mathrm{~h}$ (Table $1 \mathrm{c}$ ), and then were rapidly drop-quenched. The syntheses were performed under relatively oxidising conditions, with $f \mathrm{O}_{2}$ two log units higher than the solid buffer $\mathrm{Ni}-\mathrm{NiO}(\mathrm{NNO}+2)$. The capsules were weighted before and after experiments in order to check that no leaks occurred. The glasses were analysed in a CAMECA SX 100 electron microprobe (Camparis, Jussieu, France) and their homogeneity was checked by analysing 2 to 4 fragments of each experimental charge with, on average, 15 analyses per fragment. Their water contents were determined by Karl Fisher Titration (KFT; ISTO-Orleans) with a relative error of $\pm 5 \%$ and are homogeneous. Note that the hydrous tephritic samples from Vesuvius are partially crystallised, especially the water-poor sample $(2.1 \mathrm{wt} \%)$. Scattering in Raman measurements is thus expected for this latter glass sample.

\subsection{Raman spectroscopy}

\subsubsection{Analytical conditions}

Raman scattering was excited using an argon ion laser at wavelength of $514.5 \mathrm{~nm}$ and measurements performed with a Labram HR800 spectrometer (ENS-Lyon) manufactured by Jobin-Yvon and equipped with a Peltier-cooled CCD detector. Glasses were analysed by focusing a $\sim 1 \mu \mathrm{m}$-wide laser beam through an Olympus microscope in pseudo-confocal setting. In order to reduce the excitation volume of our pseudo-confocal system, we adopted a small confocal hole $(100 \mu \mathrm{m})$ and focused through the objective with the highest magnification $(100 \times)$. Spectra were collected in the $180-1400 \mathrm{~cm}^{-1}$ (aluminosilicate network domain) and $2800-4000 \mathrm{~cm}^{-1}\left(\mathrm{OH}+\mathrm{H}_{2} \mathrm{O}\right.$ domain) shift ranges relative to the exciting laser light (Fig. 1a). A grating of 600 grooves $/ \mathrm{mm}$ was used to cover each domain in one scan. These running conditions result in moderate resolution $\left( \pm 4 \mathrm{~cm}^{-1}\right)$, but in an intense signal even for short counting times. Average laser power was about $200 \mathrm{~mW}$ and was reduced to $20 \mathrm{~mW}$ by $1 / 10$ filtering. All spectra were obtained with the same optical configuration and 7 to 10 analyses were performed for each sample and averaged.

Laser excitation of iron-bearing (dry and hydrous) samples can result in effects ranging from local heating and oxidation up to melting and water-loss ([Behrens et al., 2006] and [Thomas et al., 2008b]). In order to minimise these effects, we choose short counting times $(3 \times 30 \mathrm{~s})$ and low laser power on samples $(7.4 \mathrm{~mW})$. Laser power was periodically checked and slightly tuned to guarantee constant energy on all samples. No melting or water-loss was detected during the analyses. Tests were performed in order to check for possible glass heating in dark samples at increasing counting times and excitation energy. No heating or oxidation effects were detected for the adopted analytical conditions. Dry and hydrous internal standards were periodically analysed at the beginning of every analytical session to correct the dependence of band intensities on delivered energy. The correction was always less than $5 \%$. 
Maximum and relative intensities of the Raman bands vary with focusing depth of the laser beam (Behrens et al., 2006). Height variation of the total water band with focal depth as a function of glass absorptivity is reported in Fig. 1b. In colourless glasses, height increases parabolically by about $60 \%$ in the first $5 \mu \mathrm{m}$, attains a maximum between 6 and $8 \mu \mathrm{m}$, and then markedly decreases at depths $>15 \mu \mathrm{m}$. Absorption effects are clearly visible in coloured glasses, in which the increase in height is less pronounced and attains a maximum value at shallower depths relative to colourless glasses. Absorption is so strong in dark glasses that Raman band height decrease immediately when focusing inside the samples (Fig. 1b). In order to compare the absolute and relative height of Raman bands in our glasses, which span a very broad range of absorptivity, we focused the laser spot on the sample surface. Typical focusing uncertainty is estimated to be $<2 \mu \mathrm{m}$ and it strongly changes the band height. However, the band ratios are only affected to a minor degree $(<0.5 \%)$.

\subsubsection{Band assignment}

Raman spectra of studied glasses exhibit two main characteristic regions (Fig. 1a): a lowfrequency region (LF: $\sim 200$ to $\sim 600 \mathrm{~cm}^{-1}$ ) and a high-frequency region (HF: $\sim 800$ to $1200 \mathrm{~cm}^{-1}$ ). The same regions occur in synthetic analogues of natural glasses (Mysen, 1988).

In synthetic analogues, the LF envelope is traditionally interpreted as the convolution of delocalised modes of vibration mostly related to: (i) symmetric stretching vibrations involving bridging oxygen $\left(\mathrm{O}^{\circ}\right){ }^{\circ} \mathrm{O}-\mathrm{T}-\mathrm{O}^{\circ}$ relative to almost stationary fourfold coordinated cations $(\mathrm{T})$ in the $\mathrm{TO}_{4}$ rings, where $\mathrm{T}=\mathrm{Si}, \mathrm{Al}$ and subordinately; to (ii) rocking motion in fully polymerised units $\left(Q^{4}\right)$; (iii) vibration of T against its tetrahedral cage with slight displacement of oxygen; (iv) T-O-T bending (in glasses containing non-bridging oxygen $\mathrm{O}^{-}$); and (v) the so-called "defect bands", possibly related to breathing modes of four- and threering structures of $\mathrm{TO}_{4}$ tetrahedra ([Mysen and Virgo, 1980], [Furukawa et al., 1981], [Sharma et al., 1981], [Galeener, 1982a], [Galeener, 1982b], [Matson et al., 1983], [McMillan, 1984], [McMillan et al., 1995] and [Pasquarello and Car, 1998]). With increasing depolymerisation of glass networks the LF Raman band maximum shifts to higher frequency irrespective of network-modifying cations, and therefore the position of the LF band correlates with the degree of depolymerisation of the silicate network (e.g. Matson et al., 1983).

The HF envelope is typical of NBO-bearing glasses, it is very weak in silica glass and it has been interpreted as the convolution of bands related to symmetric $\mathrm{T}-\mathrm{O}$ stretching vibrations of units with variable numbers of bridging oxygen $\left(Q^{n}: n\right.$ being the number of BOs) (e.g. Furukawa et al., 1981). Moreover, entry of several types of T cations in a given $Q^{n}$ unit results in distinct bands. For instance, the doublet at 1050 and $1100 \mathrm{~cm}^{-1}$ is thought to originate from two types of $Q^{3}$ species Al-O-Si and $\mathrm{Si}-\mathrm{O}-\mathrm{Si}$, respectively, and the frequency of the Al-OSi mode decreases with increasing Al content of the glass ([Matson et al., 1983] and [Sharma et al., 1983]). A line at $\sim 980 \mathrm{~cm}^{-1}$ is observed in dry feldspatic and rhyolitic iron-bearing glasses and has been attributed to anti-symmetric coupled mode of $\mathrm{Fe}^{3+} \mathrm{O}_{4}-\mathrm{SiO}_{4}$ tetrahedra ([Wang et al., 1995] and [Di Muro et al., 2008]). The HF band is thus highly sensitive to changes in the relative proportions and speciation of network-forming cations such as $\mathrm{Si}, \mathrm{Al}$, and $\mathrm{Fe}$.

The high frequency range of hydrous glasses is characterised by a broad asymmetric band which peaks at $\sim 3550 \mathrm{~cm}^{-1}$ (Fig. 1a). The position and topology of the $\mathrm{H}_{2} \mathrm{O}_{\mathrm{T}}$ envelope evolves with water content, water speciation $\left(\mathrm{H}_{2} \mathrm{O}_{m} / \mathrm{OH}\right)$ and the strength of $\mathrm{H}$-bonding ([Behrens et al., 2006] and [Di Muro et al., 2006a]). 


\subsubsection{Data treatment}

Measured Raman scattered intensity $(I(v))$ is frequency- and temperature-dependent. In particular, the intensities of the low-frequency bands are strongly influenced by the intense Rayleigh line (elastic scattering) at $0 \mathrm{~cm}^{-1}$ with respect to the bands in high-frequency domain. However, there is no consensus on the method for Raman spectra treatment (baseline fitting and correction for the dependence of Raman scattering on frequency).

In a first step, we examine the influence of the baseline fitting of uncorrected spectra on the calibration and quantification of the silicate glass water content. Fig. 2 shows the uncorrected Raman spectra of natural glasses with increasing iron content, NBO/T and SM values for rhyolite to basanite. The choice of a cubic baseline is quite straight forward for low NBO glasses (Fig. 2a). However, an increase in NBO strongly affects the topology of the intermediate region and the $I_{\mathrm{LF}} / I_{\mathrm{HF}}$ ratio (Fig. $2 \mathrm{~b}-\mathrm{d}$ ). This effect challenges the baseline fit that was performed with two distinct cubic baselines. Cubic baseline A (solid curve) is drawn between the two spectra extremities (180-280 and 1230-1600 $\mathrm{cm}^{-1}$ domains) where no signal occurs (Fig. 2a-d). However, the concave nature of the A-type baseline is highly sensitive to the length (Fig. 2a vs. c) and topology (Fig. 2c vs. d) of the fitted background. We thus imposed another "invariant" domain $\left(\sim 600-650 \mathrm{~cm}^{-1}\right)$ to fit the background of Fe-bearing glass spectra with the cubic baseline B. The latter provides a good baseline fit that applies to Fe-rich glasses when oxidised (Fig. 2b and d), as it also defines a fourth "invariant" domain $\left(\sim 850 \mathrm{~cm}^{-1}\right)$. This latter domain cannot be considered in the case of glasses having high ferrous iron content that gives rise to a shoulder in this domain (Fig. 2c) as detailed in Di Muro et al. (2008). The two baseline models produce marked differences in the topology of the extracted bands with increasing NBO/T or decreasing $\mathrm{Fe}^{3+} / \mathrm{Fe}_{\mathrm{T}}$ (Di Muro et al., 2008). The band height ratio $\left(I_{\mathrm{LF}} / I_{\mathrm{HF}}\right)$ in highly depolymerised basanite glasses is reduced by $20-30 \%$ when fitting the background with a B-type cubic baseline. However, the height of the most intense reference bands (LF in low NBO/T glasses and HF in high NBO/T glasses) is only moderately affected by baseline choice. In the present work, the background of all our Raman spectra was fitted using the B-type cubic baseline.

Several researchers have stressed the need to recalculate the raw $I(v)$ spectra to a reduced format $R(v)$ for all quantitative Raman studies (for a review, see Faurskov Nielsen, 1996), as proposed by Long (1977):

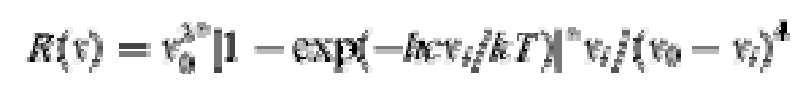

where $v_{0}$ is the frequency of laser excitation line in $\mathrm{cm}^{-1}, v_{i}$ the frequency of Raman shift, $h$ Planck's constant, $c$ light velocity, $k$ Boltzmann's constant and $T$ the sample temperature.

Thus, in a second step we examine the effect of such correction on data treatment. One advantage of the Long correction is that it applies to a much broader spectral range with respect to most reductions that are invalid at wavenumbers $>200 \mathrm{~cm}^{-1}$. The reduction procedure eliminates the effect of the Rayleigh line by converting its wing $\left(>50 \mathrm{~cm}^{-1}\right)$ into a weakly declining plateau in the studied spectral range. After correction, (a) weak lowfrequency spectral features can be identified and characterised, (b) the intensities are proportional to the intrinsic molar scattering activity for a given Raman process and (c) baseline treatment and spectral deconvolution are easier. Actually, cubic (Di Muro et al., 2008) and linear (Behrens et al., 2006) baselines can be used for background fitting of Longcorrected spectra. However, the Long-correction method with cubic baseline fitting does not 
improve significantly our water calibration for depolymerised glasses, as detailed further and already pointed out by Behrens et al. (2006). Accordingly, our data treatment was done without Long-correction.

Now, we examine the data treatment of hydrous glasses showing the $\mathrm{H}_{2} \mathrm{O}_{\mathrm{T}}$ band at $3500 \mathrm{~cm}^{-1}$. In resin embedded glass chips, the background topology is strongly dependent on glass absorptivity and shows the highest inclination in rhyolite because of fluorescence from underlying materials (Fig. 3a). This effect is particularly prominent in our pseudo-confocal system. In all analysed glasses, the background is better fitted by a cubic baseline (Fig. 3b and c). The background of the $\mathrm{H}_{2} \mathrm{O}_{\mathrm{T}}$ band is possibly approximated using a linear function ([Thomas, 2000] and [Severs et al., 2007]) only in some highly absorbing iron-rich glasses.

\section{Modelling of calibration procedures}

In this section, we review some general considerations about calibration procedures for the Raman quantitative determination of water (as iron species and others) in glasses. We identify the main parameters which control the compositional dependence of the calibration methods and quantify their effects.

In Raman spectroscopy, $\mathrm{H}_{2} \mathrm{O}_{\mathrm{T}}$ is assumed to be a proxy for the total hydrogen dissolved in glasses in the form of multiple $\mathrm{OH}^{-}$and $\mathrm{H}_{2} \mathrm{O}$ species. The simplest calibration procedure is based on the measurement of the height of the total water $\left(\mathrm{H}_{2} \mathrm{O}_{\mathrm{T}}\right)$ band that can be written as:

$$
I_{\mathrm{H} 2 \mathrm{OT}}=k \times C_{\mathrm{H} 2 \mathrm{OT}}+q
$$

with $k=I_{0} \times K(v) \times \sigma$ where $I_{0}$ is the laser power exciting the sample, $K(v)$ is a response function of optics and spectrometer, $\sigma$ is the molar scattering power of water integrated in the observation sphere (integral cross-section), $q$ is the focusing systematic error (Fig. 1b) and $C$ is the total water weight concentration. Eq. (1) is valid if the laser beam is focused on the sample surface, only.

Using the external calibration procedure Eq. (1) reduces to

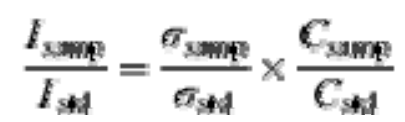

This equation is valid if $q$ is zero (no focusing errors) or if the focusing error is identical on both the unknown and the standard $\left(q_{\mathrm{samp}}=q_{\mathrm{std}}\right)$, and if the compositions of both the unknown sample and standard are closely similar owing to the dependence of the scattering crosssection $\sigma$ on glass composition. Furthermore, external calibration requires an accurate determination of the $\mathrm{H}_{2} \mathrm{O}_{\mathrm{T}}$ band height on both the standard and the unknown sample.

Using internal calibration overcomes possible focusing bias. In such a procedure, the height of the $\mathrm{H}_{2} \mathrm{O}_{\mathrm{T}}$ band is scaled to that of a reference band (RB, e.g. the LF or HF bands of glasses): 


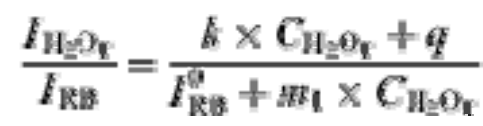

where $I_{\mathrm{RB}}$ is the height of the reference band (LF or HF) in the hydrous glass, $I_{\mathrm{RU}}^{\mathrm{g}}$ in anhydrous glass, and $m$ is the parameter sensitive to the effect of water (or other species) on glass polymerisation and thus on $I_{\mathrm{KB}}^{\mathbb{E}}$. In this equation, the compositional dependence arises from: (i) the possible dependence of $\mathrm{H}_{2} \mathrm{O}_{\mathrm{T}}$ cross-section and speciation on the glass composition; (ii) the change of $I_{\mathrm{k}}^{\mathbb{0}}$ with glass bulk composition; and (iii) the possible intensity variation of the reference band with total water content, for a given bulk composition. In a given set of reference glasses, $I_{\mathrm{RB}}$ changes with increasing $\mathrm{H}_{2} \mathrm{O}_{\mathrm{T}}$ concentration because of the well-known influence of dissolved water on glass structure. A decrease of $I_{\mathrm{RB}}$ has the most drastic effect on the calibration curves (i.e. $m=-90$; Fig. 4a). Hence, non-linear calibration established on an incomplete set of reference glasses can result in apparent lines that intercept one of the diagram axes. Moreover, the parameter $m$ is sensitive to the dissolved water concentration in our experimental range (0-7 wt $\%)$, the water speciation and its relative effect on glass structure (as ferric iron content). The occurrence of these phenomena can be detected as clear kinks in the evolution of the $\underline{I}_{\mathrm{H} 2 \mathrm{OT}} / I_{\mathrm{RB}}$ with increasing water whose shape again will depend on the decreasing or increasing effect of water on $I_{\mathrm{RB}}$ (Fig. 4b). The application of the internal procedure to the analysis of an unknown clearly requires that the sample has a bulk composition as close as possible to that of the standard ([Behrens et al., 2006] and [Di Muro et al., 2006a]) and that the dissolved analyte has only minor effect on glass structure in the concentration range of interest.

In a previous work, we have shown that the height ratio between the two main reference bands observed in Raman spectra of natural alumino-silicate glasses decreases with increasing depolymerisation (Di Muro et al., 2006b). We can, therefore, rearrange Eq. (3) in the form:

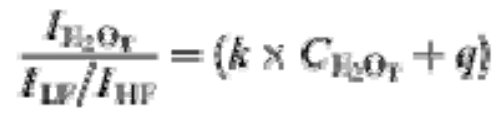

$$
\begin{aligned}
& -\left(\frac{P_{\mathrm{HF}}^{\theta_{F}}+m_{2} \times C_{\mathrm{H}_{2} \mathrm{O}_{\mathrm{K}}}}{f_{\mathrm{LF}}^{0}-m_{1} \times C_{\mathrm{H}_{2} \mathrm{O}_{\mathrm{K}}}}\right) \\
& =\frac{k \times \mathrm{C}_{\mathrm{H}_{3} \mathrm{O}_{4}}+q}{(f(\mathrm{NBO} / \mathrm{T} ; \mathrm{SM}))}
\end{aligned}
$$

The function $f$ that describes the evolution of the $I_{\mathrm{LF}} / I_{\mathrm{HF}}$ ratio with a structural/compositional parameter such as NBO/T or SM is derived in the following paragraphs. This approach allows us to either define calibration lines adapted to the unknown composition on the basis of the only knowledge of the parameter $k$ (Eq. (4)) or to calculate the water concentration in an unknown glass sample as:

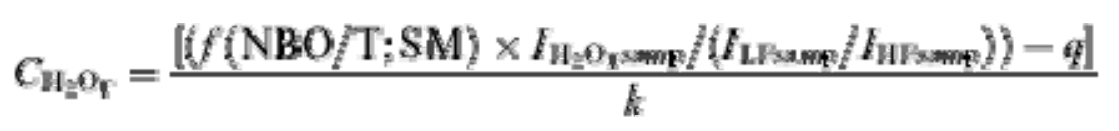

In this last case, an iterative procedure is required to adjust the structural parameter to the estimated water content. 


\section{Spectral evolution with bulk compositions}

In our study, the influence of the bulk sample composition is expressed through two different composition-dependent parameters, $\mathrm{NBO} / \mathrm{T}$ and $\mathrm{SM}$, commonly used to represent, at a first approximation, the degree of polymerisation of the silicate framework.

For dry glasses, these parameters were tentatively calculated assuming that all $\mathrm{Fe}^{3+}$ acts as a network-former cation and $\mathrm{Fe}^{2+}$ as a network-modifier. It is however known that, in highly depolymerised silicate melts, $\mathrm{Fe}^{2+}$ could act as network-former (Cooney and Sharma, 1990). We also assumed that half of the $\mathrm{FeO}_{\text {tot }}$ (in wt\%) partitions as $\mathrm{FeO}$ and the other half as $\mathrm{Fe}_{2} \mathrm{O}_{3}$, that implies a nearly constant $\left[\mathrm{Fe}_{2} \mathrm{O}_{3} /\left(\mathrm{FeO}+\mathrm{Fe}_{2} \mathrm{O}_{3}\right)\right]$ mass ratio value of about 0.5 . The latter value is realistic and fits with the average iron oxidation state of most of the synthesised anhydrous glasses (D. Giordano). Note a deviation from this value of 0.5 may introduce scattering at intermediate values of NBO/T and SM (e.g. Fig. 6). Instead, we used the measured ferric/ferrous ratios in the case of the two basaltic glass sets having variable oxidation state.

For hydrous glasses, the structural parameters were calculated for "dry" composition in order to allow a quick comparison in terms of bulk compositions between hydrous and dry glass sets.

\subsection{Composition influence in anhydrous glasses}

Fig. 5a shows the general evolution of the HF and LF bands related to vibrations of the glass network for three variously depolymerised melts from rhyolite to basanite. With increasing depolymerisation, the LF band broadens, shifts to higher frequency and decreases in height. In our glass set, the position of the LF band progressively shifts from 485 to $500 \mathrm{~cm}^{-1}$ in glasses with $\mathrm{NBO} / \mathrm{T}$ ranging from 0.01 to 0.15 . The LF band broadening with increasing NBO/T is mostly due to the increase in intensity of a mode at $\sim 580 \mathrm{~cm}^{-1}$. This mode prevails in highly depolymerised basanitic and tephritic glasses $(0.5<\mathrm{NBO} / \mathrm{T}<1.16)$. Whilst the LF height decreases, the height of the HF envelope increases and the massif shifts to lower frequency. In $\mathrm{Si}, \mathrm{Al}-$ rich and iron-poor rhyolitic glasses, the HF envelope peaks at $995-1030 \mathrm{~cm}^{-1}$ and has a marked shoulder at $1100-1150 \mathrm{~cm}^{-1}$. With increasing NBO/T and total iron content, the lowfrequency side of the HF envelope becomes increasingly intense and the band position moves at $950-960 \mathrm{~cm}^{-1}$. With a change from low- to high-NBO/T in glasses, the intermediate band shifts from 800 to $700 \mathrm{~cm}^{-1}$. The observed trend from rhyolite to basanite is coherent with progressive depolymerisation of the glasses and increasing amounts of iron in the silicate network. The increase in height and negative shift of the HF band essentially reflect the augmentation of $Q^{n}$ units with low $\mathrm{n}$ and the enhanced presence of iron in fourfold coordination. The $I_{\mathrm{LF}} / I_{\mathrm{HF}}$ ratio exponentially decreases from 3 to 2 in low NBO/T rhyolitic glasses and down to $0.6-0.3$ in high NBO/T mafic basanites and tephrites (Fig. 6a). The rate of decrease is very abrupt in the $\mathrm{NBO} / \mathrm{T}$ range $0-0.1$, while the $I_{\mathrm{LF}} / I_{\mathrm{HF}}$ ratio becomes almost constant in high NBO/T glasses. A comparable but smoother global evolution is observed when considering the $I_{\mathrm{LF}} / I_{\mathrm{HF}}$ ratio evolution as a function of SM (Fig. 6b). We observe the same feature when the area ratio (shadowed area) is considered. The adoption of the SM parameter to describe the structural changes reduces the standard deviation from the general trend to $<10 \%$. The main difference between height and area ratios is found in highly polymerised glasses, the determination of band areas resulting in smaller increase of $I_{\mathrm{LF}} / I_{\mathrm{HF}}$ ratio with decreasing NBO/T or SM (Fig. $6 a$ and b). On the basis of the observed trends, the $\mathrm{LF}$ envelope is the ideal reference band for internal calibrations for glasses with $\mathrm{NBO} / \mathrm{T}<0.2$ 
such as rhyolites, trachytes, iron-poor phonolites, dacites, andesites and latites. Conversely, the HF envelope becomes a potential reference band for more depolymerised $(0.2<\mathrm{NBO} / \mathrm{T}<1.1)$ intermediate and mafic glasses. Moreover, on the basis of the decrease in the $I_{\mathrm{LF}} / I_{\mathrm{HF}}$ ratio we can expect a significant effect of bulk chemical composition on internal Raman calibrations in polymerised glasses with $\mathrm{NBO} / \mathrm{T}<0.2$ and a reduced composition dependence at higher NBO/T.

\subsection{Influence of iron oxidation state}

As discussed above (Section 2.2.2.), the glass iron oxidation state potentially affects the Raman spectra topology and particularly the HF envelop. We have thus explored such an effect by analysing the two sets of anhydrous basaltic glasses with variable $\left[\mathrm{Fe}^{3+} / \mathrm{Fe}_{\mathrm{T}}\right]$ ratios, significantly differing in their NBO/T and SM values. Both parameters decrease with addition of increasing amounts of $\mathrm{Fe}^{3+}$, assuming that this species acts as a network-former, while $\mathrm{Fe}^{2+}$ plays essentially a role of network modifier (Table $1 \mathrm{~b}$ ). The NBO/T and SM values vary, respectively, in the range 0.35-0.53 $(>33 \%)$ and $28.9-32.7(\sim 13 \%)$ in the Stromboli glasses and $0.43-0.59(>37 \%)$ and 31.4-34.2 $(\sim 10 \%)$ in the Etna samples. Raman spectra of these basalts reveal only minor changes in band position, shape and height. The evolution of the spectra topology as a function of iron oxidation states is small for both glass sets, although some modifications are noticed in the Stromboli basalt (Fig. 5b and c). The LF and HF band positions remain fixed at $497 \pm 4 \mathrm{~cm}^{-1}$ (LF of Str and Et sets) and $972 \pm 4 \mathrm{~cm}^{-1}$ (HF of Et set) in the $\mathrm{Fe}^{3+} / \mathrm{Fe}_{\mathrm{T}}$ ratio range $0.05-0.50$. Only the HF band of Str glasses is affected by a negative shift of $40 \mathrm{~cm}^{-1}$ (from 997 to $959 \mathrm{~cm}^{-1}$ ) in the $\mathrm{Fe}^{3+} / \mathrm{Fe}_{\mathrm{T}}$ range $0.05-0.87$ (Fig. 5b). In Stromboli glasses, moderate broadening of the LF band occurs with increasing $\mathrm{Fe}^{3+} / \mathrm{Fe}_{\mathrm{T}}$ ratios because of the intensity increase of a shoulder at about $560 \mathrm{~cm}^{-1}$.

The relative heights of LF and $\mathrm{HF}$ envelopes linearly increase in the $\mathrm{Fe}^{3+} / \mathrm{Fe}_{\mathrm{T}}$ ratio range 0.05-0.46 and then remain constant in more oxidised glasses (Table 1b). An increase in $I_{\mathrm{LF}} / I_{\mathrm{HF}}$ ratio of $19-22 \%$ is measured in the basaltic glass (Str, Et) sets. Increase of the $I_{\mathrm{LF}} / I_{\mathrm{HF}}$ ratio in the basaltic glasses with decreasing NBO/T or SM produces only a slight displacement of their representative points along the general trend evolution of the dry glasses (Fig. 6a and b). These results support the idea that in natural mafic glasses, bulk composition rather than the iron oxidation state controls the main evolution of the topology of Raman spectra. Instead, noticeable evolution of the Raman spectra topology and a strong linear increase of the $I_{\mathrm{LF}} / I_{\mathrm{HF}}$ ratio has been demonstrated by Magnien et al. (2006) in Al-free synthetic mafic glasses (NBO/T: 1.9-1.2) in the $\mathrm{SiO}_{2}-\mathrm{CaO}-\mathrm{MgO}-\mathrm{Na}_{2} \mathrm{O}-\mathrm{FeO}$ system and in natural iron-rich peralkaline rhyolites (Di Muro et al., 2008). The reduced sensitivity of the Raman spectra recorded in our natural basaltic glasses with respect to iron oxidation state could be explained by the competition between $\mathrm{Al}$ and $\mathrm{Fe}$ as network formers. The absence of $\mathrm{Al}$ in the system studied by Magnien et al. (2006) is likely to favour stronger and faster variation of the glass structure as a function $\mathrm{Fe}^{3+} / \mathrm{Fe}_{\mathrm{T}}$ ratios.

\subsection{Influence of water content on Raman spectra}

\subsubsection{The $\mathrm{OH}-\mathrm{H}_{2} \mathrm{O}$ stretching domain $\left(3000-4000 \mathrm{~cm}^{-1}\right)$}

In all water-bearing glasses, increasing the amount of dissolved water induces a change in the peak position, height, area and the shape of the $\mathrm{OH}$-stretching band. That also introduce proportional increase of both height and area of the $\mathrm{H}_{2} \mathrm{O}_{\mathrm{T}}$ band (Fig. 5d). 
Increasing $\mathrm{OH} / \mathrm{H}_{2} \mathrm{O}_{m}$ ratios and $\mathrm{H}$-bonding strength from high to low hydrated glasses likely control the topological evolution of this band ([Chabiron et al., 2004], [Zajacz et al., 2005], [Behrens et al., 2006] and [Di Muro et al., 2006a]). Decreasing $\mathrm{H}_{2} \mathrm{O}_{\mathrm{T}}$ concentration, in the range between $7-5$ and $1.2 \mathrm{wt} \%$ causes a small positive shift of $10-20 \mathrm{~cm}^{-1}$ with respect to $3550 \mathrm{~cm}^{-1}$ in all glass sets except the Fe-rich "Pollena" phonolite for which the shift is larger $\left(30 \mathrm{~cm}^{-1}\right)$ within a more restricted range of dissolved water content $\left(\mathrm{H}_{2} \mathrm{O}_{\mathrm{T}}: 6.7-2.5 \mathrm{wt} \%\right)$. In water-poor glasses $(<1.2 \mathrm{wt} \%)$, a different evolution is observed. With decreasing water concentrations the shift becomes slightly negative from 3570 to $3560 \mathrm{~cm}^{-1}$ for a $\mathrm{H}_{2} \mathrm{O}_{\mathrm{T}}$ content varying from 0.8 to $0.4 \mathrm{wt} \%$ in the basaltic Et glasses. Larger negative shifts and evolution from uni- to poly-modality of the $\mathrm{H}_{2} \mathrm{O}_{\mathrm{T}}$ band were already reported for water-poor $(<0.9 \mathrm{wt} \%)$ phonolites (Di Muro et al., 2006a) and rhyolites (Arias et al., 2006). In the present study, the occurrence of polymodality with decreasing $\mathrm{H}_{2} \mathrm{O}_{\mathrm{T}}$ content has not been observed in the mafic glasses and the $\mathrm{H}_{2} \mathrm{O}_{\mathrm{T}}$ band always defines one asymmetric band. Finally, the asymmetric $\mathrm{H}_{2} \mathrm{O}_{\mathrm{T}}$ band of water-rich glasses (7-5 wt $\%$ ) of rhyolitic, basaltic, tephritic and basanitic composition peaks at $3550-3570 \mathrm{~cm}^{-1}$, while its position is shifted to a lower frequency $\left(3500-3510 \mathrm{~cm}^{-1}\right)$ in phonolites.

\subsubsection{The silicate network domain (180-1300 $\left.\mathrm{cm}^{-1}\right)$}

The evolution of the Raman spectra topology with $\mathrm{H}_{2} \mathrm{O}_{\mathrm{T}}$ contents in natural silicic glasses (rhyolites and phonolites) has already been described in detail in (Di Muro et al., 2006a) and (Di Muro et al., 2006b). Following these authors, the topology of both LF and HF envelopes in the most polymerised systems (rhyolites) undergoes pronounced changes with increasing water contents. The aspect ratio (height/half-width) of the LF band increases, and its position displays a marked positive shift, possibly related to a decrease in the average $\mathrm{T}-\mathrm{O}-\mathrm{T}$ angle (McMillan and Remmele, 1986). The relative proportions of the bands forming the HF envelope changes with a strong increase of a line at $\sim 910 \mathrm{~cm}^{-1}$, possibly related to the formation of T-OH units (Zotov and Keppler, 1998).

Here, we focus on the topological evolution of the three available sets of hydrous mafic glasses (Etna basalt, Vesuvius tephrite and Sommata basanite). Topological effects of increasing amounts of $\mathrm{H}_{2} \mathrm{O}_{\mathrm{T}}$ differ in the three glass sets.

In the Etna basalt set, the height of the LF envelope increases when water contents increase from 0.4 to $3.04 \mathrm{wt} \%$ whereas the HF envelope decreases (Fig. 5e). Both in the HF and LF domain, the height variations can be observed with no frequency position changes (LF: $505 \mathrm{~cm}^{-1}$; HF: $967 \mathrm{~cm}^{-1}$ ).

In the Vesuvius tephrite (not shown here), both LF and HF envelopes decrease in height with increasing $\mathrm{H}_{2} \mathrm{O}_{\mathrm{T}}$. The decrease of the LF massif is associated with an increase of the height ratio between the $490 \mathrm{~cm}^{-1}$ band and its shoulder at $560 \mathrm{~cm}^{-1}$. As in the Etna basalt set, these two main bands are not affected by any shift and peak at $491 \mathrm{~cm}^{-1}$ for the LF band and $955 \mathrm{~cm}^{-1}$ for the HF band.

In the Sommata basanite series, the LF height envelope increases with increasing $\mathrm{H}_{2} \mathrm{O}_{\mathrm{T}}$ (Fig. 5f). This variation is associated with an increase in height of the $550 \mathrm{~cm}^{-1}$ shoulder. In the glass with the highest water content $(4.95 \mathrm{wt} \%)$, the 490 and $550 \mathrm{~cm}^{-1}$ bands are split and form a distinct doublet on the LF envelope. The HF height decreases only slightly and its position remains fixed at $964 \mathrm{~cm}^{-1}$. 
As shown above, the $I_{\mathrm{LF}} / I_{\mathrm{HF}}$ ratio is positively correlated with glass polymerisation. The dissolution of increasing amounts of water, a potentially depolymerising agent, produces a counterintuitive linear increase in the $I_{\mathrm{LF}} / I_{\mathrm{HF}}$ ratio in all glass sets (Fig. $6 \mathrm{c}$ and d). As already observed by Giordano et al. (2008), this pattern suggests that, although water is normally considered to act as a network modifier, it plays a somewhat different role in the structure of the silicate melts relative to other network-modifying cations. However, the rate of $I_{\mathrm{LF}} / I_{\mathrm{HF}}$ increase per weight percent dissolved $\mathrm{H}_{2} \mathrm{O}_{\mathrm{T}}$ depends on the initial (dry) glass degree of polymerisation as it increases from $15-16 \%$ in silicic glasses to $32-46 \%$ in mafic glasses (Table 1c). The observed spectra evolution in the less depolymerised glass set of mafic glasses (Etna basalt) closely resembles that found by Mysen and Virgo (1980) in synthetic soda-melilite glasses $\left(\mathrm{NaCaAlSi}_{2} \mathrm{O}_{7} \cdot \mathrm{H}_{2} \mathrm{O}\right)$. These authors explained the shape evolution and height decrease of the HF band as the effect of water dissolution to form $\mathrm{OH}$ groups associated with $\mathrm{Si}^{4+}$ and modification of the ratio between $Q^{4}$ and $Q^{3}$ units. Spectra deconvolution of the most depolymerised glasses (tephrite and basanite) reveals that the observed height changes of the LF and HF bands are mainly controlled by two components at 570 and $1000 \mathrm{~cm}^{-1}$. The intensity of the high-frequency side of the LF envelope has classically been correlated with glass depolymerisation (Mysen, 1988). The band near $1000 \mathrm{~cm}^{-1}$ has been attributed to T-OH stretching ([Stolen and Walrafen, 1976], [Mysen and Virgo, 1980] and [Mysen et al., 1980a]). Hence, our data suggest that the proportion of water dissolved as silenols $(\mathrm{T}-\mathrm{OH})$ decreases with increasing glass depolymerisation.

\subsection{Prediction of $I_{\mathrm{LF}} / I_{\mathrm{HF}}$ ratio}

Fig. $6 \mathrm{a}$ and $\mathrm{b}$ show the evolution of $I_{\mathrm{LF}} / I_{\mathrm{HF}}$ ratio for anhydrous glasses that can be easily predicted by using simple expressions. In particular, the variation of the $I_{\mathrm{LF}} / I_{\mathrm{HF}}$ ratio as a function of the NBO/T and the SM parameters ( $f(\mathrm{NBO} / \mathrm{T}$; SM) of Eqs. (4) and (5)) can be expressed by equations of the following form:

$$
\mathrm{LF} / \mathrm{HF}=a+\frac{a l}{1+a 2 \times(\mathrm{NBO} / \mathrm{T})_{\text {q }}}
$$

and

$$
\mathbf{L F} / \mathrm{HF}=b+\frac{b 1}{b 2+\mathrm{SM} A_{m y}}
$$

where $\mathrm{SM}_{\mathrm{dry}}$ and $\mathrm{NBO} / \mathrm{T}_{\mathrm{dry}}$ are the values of polymerisation degree parameters for dry compositions and $a, a 1, a 2, b, b 1, b 2$ are the adjustable parameters.

On the other hand, Fig. $6 \mathrm{c}$ and $\mathrm{d}$ show the evolution of the $I_{\mathrm{LF}} / I_{\mathrm{HF}}$ ratio measured in glass samples having variable amounts of dissolved water (i.e. from anhydrous to about $7 \mathrm{wt} \%$ ).

The evolution of the $I_{\mathrm{LF}} / I_{\mathrm{HF}}$ ratio for the whole range of anhydrous and hydrous composition investigated here can be predicted using the Eqs. (8) and (9), as it follows: 


$$
\begin{aligned}
\mathrm{LF} / \mathrm{HF}= & \left(A 1+\frac{B 1}{1+C 1 \times(\mathrm{NBO} / \mathrm{T})_{\mathrm{Hy}}}\right) \\
& +\left(D 1 \times N_{\mathrm{H}_{2} \mathrm{O}}^{2}+E 1 \times N_{\mathrm{H}_{2} \mathrm{O}}+F 1\right)
\end{aligned}
$$

and

$$
\begin{aligned}
\mathrm{I} . \mathrm{H} / \mathrm{HF}= & \left(A 2+\frac{B 2}{C 2+\$ M_{B \gamma}}\right) \times(1+D 2 \\
& \left.\times N_{\mathrm{H}_{0} \mathrm{O}}^{2}+E 2 \times N_{\mathrm{H}_{2} O}+F 2\right)
\end{aligned}
$$

where $A 1, A 2, B 1, B 2, C 1, C 2, D 1, D 2, E 1, E 2, F 1, F 2$ are adjustable parameters as reported in Table $3 ; \underline{N}_{\mathrm{H} 2 \mathrm{O}}$ (in mole $\%$ ) is the amount of water dissolved in the glass and $\mathrm{SM}_{\mathrm{dry}}$ and $\mathrm{NBO} / \mathrm{T}_{\text {dry }}$ are calculated values as at Eqs. (6) and (7).

There is an excellent agreement between the measured and the predicted values of the $I_{\mathrm{LF}} / I_{\mathrm{HF}}$ ratio. This ratio also increases with addition of water and it is positively correlated with the values of the NBO/T and SM parameters. The following expressions of the $f(\mathrm{NBO} / \mathrm{T} ; \mathrm{SM})$ are used to describe the $I_{\mathrm{LF}} / I_{\mathrm{HF}}$ ratio variation also as a function of water content.

\section{Influence of spectral treatment and glass composition on micro-Raman calibration procedures}

\subsection{Effect of spectral treatment}

In this section we consider the effects of data correction and band characterisation (area or intensity) on the linearity and composition dependence of the calibration lines for the determination of the water content in depolymerised glasses.

\subsubsection{Uncorrected vs. Long-corrected spectra}

Fig. 7 shows the calibration curves for water determination in mafic glasses based on raw and Long-corrected band heights. The calibration curves have much steeper slopes when using Long-corrected data than uncorrected raw data using both LF (Fig. 7a and b) and HF (Fig. 7c and d) as internal calibration reference bands. Moreover, the slope variation and splitting are more pronounced when using both the Long-corrected data treatment and the HF band for $\mathrm{H}_{2} \mathrm{O}_{\mathrm{T}}$ normalisation (Fig. 7c and d). Instead, a single calibration curve fits our data points for mafic glasses having water contents between 1 and $5 \mathrm{wt} \%$ when LF is selected as the reference band (Fig. 7a and b). A clear kink is observed in Fig. 7a and b for low water contents $(<1 \mathrm{wt} \%)$ because of the non-linear increase of $\underline{I}_{\mathrm{H} 2 \mathrm{OT}} / I_{\mathrm{LF}}$ ratio with water content as discussed above. In contrast, calibration curves for which the $\mathrm{H}_{2} \mathrm{O}_{\mathrm{T}}$ band is normalised to the $\mathrm{HF}$ band converge to the axis origin (Fig. 7c and d). 


\subsubsection{Comparison between area- and intensity-based calibration curves}

Fig. 8 shows the calibration lines derived from both internal and external procedures. All the data can be fitted with one single line when using external calibrations based on measurement of the $\mathrm{H}_{2} \mathrm{O}_{\mathrm{T}}$ band height (Fig. 8a and b). Linear regression of area data is slightly worse than that of height data because of the larger error associated with area measurements and possible compositional effect.

Internal calibrations of the total water band height (Fig. 8c and e) and area (Fig. 8d and f) normalised to either LF or HF bands show that area data treatment enhances the composition dependence of water calibration procedures. This effect is particularly significant in the calibrations for the analysis of depolymerised glasses (Fig. 8e and f). A single polynomial fit describes the evolution of the $I_{\mathrm{H} 2 \mathrm{OT}} / I_{\mathrm{LF}}$ height ratio with increasing dissolved water content (Fig. 8c).

\subsection{Effect of glass composition}

In the previous section, we have shown that calibrations based on Long-corrected data and area measurements have larger composition dependence than those derived from uncorrected band intensities. Accordingly, only intensity data, derived from uncorrected spectra, are considered in the following discussion. Band intensities, intensity ratios and corresponding errors are reported for each glass sample in Table 2.

\subsubsection{External calibration}

Hydrous glass sets of basaltic, basanitic, tephritic, phonolitic and rhyolitic composition, define a single linear calibration passing through the axis origin when the height of the $\mathrm{H}_{2} \mathrm{O}_{T}$ band is correlated with the total water content (Fig. 8a and b). This method appears to be very effective in reducing chemical composition dependence of micro-Raman calibration. It should be noted that the observed data scattering is due to small differences in beam focusing and/or laser energy from one session of measurement to another one. Actually, the difference in slopes of calibration lines of transparent (polymerised) and absorbing (depolymerised) glasses is mainly due to these combined effects. We have verified that all samples, regardless of their compositions, should be aligned along the same calibration curve if analysed during the same session and under the same analytical conditions. Moreover, the apparent positive intercept observed for transparent glasses is related to bias introduced by the focusing error on the band height measurement (Fig. 1b). Actually, in colourless glasses the $\mathrm{H}_{2} \mathrm{O}_{\mathrm{T}}$ band height increases by about $50 \%$ in the first $3 \mu \mathrm{m}$ whereas the absorption in coloured glasses is already significant at this depth. Hence, errors in focusing on the surface in transparent glasses easily overestimate the $\mathrm{H}_{2} \mathrm{O}_{\mathrm{T}}$ band height. In order to overcome this problem, the laser beam could be focused at the depth where the signal intensity achieves its maximum value $(5 \mu \mathrm{m}$ in transparent glasses). However, this depth changes with glass composition and analytical setting (e.g. confocality, laser wavelength). Moreover, focusing in depth does not represent a viable procedure for the analysis of micro-crystallised or micro-vesicular samples. Hence, in order to avoid a significant effect of the glass absorptivity on the measured height of the $\mathrm{H}_{2} \mathrm{O}_{\mathrm{T}}$ band, the laser beam must be correctly focussed at the sample surface. The positive intercept defines the correction parameter $q$ in Eq. (1). Our experience, for all analysed glass sets, is that $q$ becomes zero if very precise focusing on the glass surfaces is achieved. 


\subsubsection{LF internal calibration}

Divergence between the calibration curves of polymerised and depolymerised glasses is observed when the height of the $\mathrm{H}_{2} \mathrm{O}_{\mathrm{T}}$ band is normalised to that of the LF envelope as illustrated by the Fig. 8c, in which silicic (rhyolitic, phonolitic) and mafic (basalt, tephrite, basanite) glasses plot on two slightly distinct trends. Calibrations based on band areas (Fig. 8d) exhibit larger composition dependence, but are linear for all compositions. The polynomial calibration line for mafic glasses in Fig. 8c is comparable with that reported for basaltic glasses with $0-4.7 \mathrm{wt} \% \mathrm{H}_{2} \mathrm{O}_{\mathrm{T}}$ by Behrens et al. (2006). The bending of the calibration with increasing water contents can be attributed to the dependence of the LF envelope on increasing water content and depolymerisation (Fig. 4). More precisely, in polymerised phonolites, the height of the LF undergoes a smooth and linear decrease with increasing water content: $\sim 5 \%$ in iron-rich phonolites $\left(\mathrm{H}_{2} \mathrm{O}=2.5-6.7 \mathrm{wt} \%\right)$ and $\sim 10 \%$ in iron-poor phonolites $\left(\mathrm{H}_{2} \mathrm{O}=2.4-6.8 \mathrm{wt} \%\right.$, Table 2$)$. On the contrary, the LF height progressively increases to about $45 \%$ in basanite in the range $0.79-4.95 \mathrm{wt} \% \mathrm{H}_{2} \mathrm{O}_{\mathrm{T}}$ (e.g. Sommata glass, Table 2), following a polynomial function. An intermediate evolution of the LF height with increasing water is observed in Etna basaltic glasses with a decline of about 17\% in water-poor glasses $(0.40-1.75 \mathrm{wt} \%)$, and an increase of $29 \%$ at higher water contents (1.75-4.95 wt \%). Bending of calibration curves in mafic glasses is thus related to the non-linear effects of water dissolution on glass structure and LF topology.

As a whole, the slopes of LF calibration lines increase with NBO/T values. This trend is clearly related to the progressive decrease of the LF intensity with decreasing polymerisation degree (Fig. 6). Finally, our data suggest that internal calibration using the area of the LF band for normalisation is appropriate for quantifying water content dissolved in both polymerised and depolymerised glasses because: (i) the LF band is very intense and affected by small errors in baseline subtraction at low NBO/T; (ii) the water dissolution has a linear effect on the area of this band in all glass sets. In contrast, LF calibrations based on the band heights are questionable for depolymerised glasses.

\subsubsection{HF internal calibration}

All hydrous glasses plot on distinct linear trends when the intensity of the $\mathrm{H}_{2} \mathrm{O}_{\mathrm{T}}$ band is normalised to the HF reference band (Fig. 8e and f). Calibration lines cross the origin axis with a very small scattering $\left(R^{2}\right.$ up to 0.99$)$ and allow precise measurement of total dissolved water content. The slopes decrease with increasing NBO/T and are steeper than with the LF internal calibration. Steep slopes are a pre-requisite for the definition of precise calibrations, but possibly enhance the composition dependence. With this procedure, the three mafic sets and the two phonolitic sets (iron-poor and iron-rich) define diverging calibrations.

Composition dependence is higher in calibrations based on band areas (Fig. 8e). Slope decrease is clearly controlled by increasing HF intensity with NBO/T and iron content (Fig. 5a). The observed linearity is instead due to the small linear decrease in the HF band height with increased water content for each composition (Table 2; Eq. (3)).

The height of the HF bands is inversely proportional to the glass polymerisation degree and, in a complex way, to the iron content and iron oxidation state (Di Muro et al., 2008). We demonstrate that the redox state of iron has negligible effect on the calibration curves of mafic glasses (Fig. 6b). Actually, the HF height increases by only $\sim 10 \%$ with an increase in the $\left[\mathrm{Fe}^{3+} / \mathrm{Fe}_{\mathrm{T}}\right]$ ratio from 0.098 to 0.48 (Et basalt set). The slope of the HF calibration line in Etna basalts would be significantly affected (error bars above $10 \%$ ) only by iron oxidation changes 
$>35 \%$. It becomes even less sensitive to the iron speciation for tephritic and basanitic compositions. Calibrations based on band heights are affected by a limited matrix effect and are the most effective in reducing the influence of heterogeneities in iron oxidation state in both standards and unknowns. The HF band therefore represents the most suitable reference band for the internal calibration procedure when analysing depolymerised glasses.

\section{Calculation of dissolved water content: a new approach}

\subsection{Prediction of calibration line slope}

Here, we examine variations in the calibration line slopes when using the HF internal calibration methods as a function of NBO/T and SM parameters (Fig. 9). The LF band normalisation procedure is not effective in predicting the evolution of the calibration line slopes because of the scattering induced by the strong dependency of the LF on glass polymerisation and water content. Instead, the HF internal calibration method provides much better fit providing a means for understanding the relationship between the slope of calibration lines and the glass composition via a structural parameter. The decrease rate of the slope for linear calibrations based on band areas as a function of the compositional parameters NBO/T (Fig. 9a) or SM (Fig. 9b) has been calculated on the basis of: (a) the modelled LF/HF trend (Fig. 6a and b) and the constant slope of external calibrations for water (Fig. 8). The expected trend (dotted curve) fits the literature data and our own calibrations and demonstrates that our model is able to capture the matrix effect that affects the HF procedure of internal calibration. The matrix effect progressively decreases from silicic to intermediate compositions and is very small in mafic glasses. The slope of calibration line can thus be predicted and eventually corrected when the composition of the available glass standard differs from that of the unknown samples. However, this approach would require systematic measurements on three different hydrous sets of standard glasses at least.

\section{.2. Calculation of dissolved water content}

Calibration of Eq. (5) allows the construction of a very simple equation able of predict the water concentration $\left(C_{\mathrm{H} 2 \mathrm{OT}}\right.$ in wt $\left.\%\right)$ dissolved in a glass of known bulk composition, such that:

$$
C_{\mathrm{H}_{2} \mathrm{O}_{\mathrm{K}}}=\frac{\left(\mathrm{TOT}_{\mathrm{N}}\right) \times\left(\mathrm{I}_{\left.\mathrm{H}_{2} \mathrm{O}_{N}\right)}\right)}{k}
$$

where $\mathrm{TOT}_{N}$ is the expected LF/HF band height ratio of the unknown determined with Eqs. (8) and (9), $\underline{I}_{\mathrm{H} 2 \mathrm{ON}}$ is the ratio $\underline{I}_{\mathrm{H} 2 \mathrm{O}} /\left(I_{\mathrm{LF}} / I_{\mathrm{HF}}\right)$ measured on the hydrous unknown sample and $k$ is the slope of Eq. (1). In order to apply the equation: (a) the theoretical evolution of $\mathrm{TOT}_{N}$ must be calibrated on a set of dry and hydrous glass standards and the composition of the unknown must be assessed; (b) $k$ is daily calibrated on a set of hydrous standards; and (c) $\underline{I}_{\mathrm{H} 2 \mathrm{ON}}$ is obtained by the measurement on the unknown after baseline subtraction. Such a procedure allows the use of any set of hydrous glass standards even very different from the unknown. However, $\mathrm{TOT}_{N}$ value includes the sample $\mathrm{H}_{2} \mathrm{O}_{\mathrm{T}}$ content (Eqs. (8) and (9)) that is roughly estimated by using external calibration. Such approximation does not introduce significant error on the final results. 
There is good agreement between the water content calculated using Eq. (10) and those determined on the bulk glass fragments by independent methods (Table 1a). The regressions presented in Fig. 10a and $\mathrm{b}$ give the following relationship:

$$
\begin{aligned}
& Y(\text { wi } \%)=1.0192 \times X(\text { w } \%)+0.0786 \\
& \text { Regression data }: r^{2}=0.91 ; \quad S D=0.15 ; \quad n=27 \\
& Y(\text { wi } \%)=1.0289 \times X(\text { we } \%)-0.0857 \\
& \text { Regression data }: r^{2}=0.96 ; \quad S D=0.06 ; \quad n=27
\end{aligned}
$$

where $X$ is the reference water content, $Y$ is the predicted water content, $r$ is the correlation coefficient, $\mathrm{SD}$ is the standard deviation of the fit and $\mathrm{n}$ is the number of data points. Eqs. (11) and (12) are obtained as a function of $\mathrm{NBO} / \mathrm{T}$ and SM parameters, respectively.

A better correlation is observed with the SM parameter than NBO/T. This is consistent with the observation that $I_{\mathrm{LF}} / I_{\mathrm{HF}}$ ratios on anhydrous glasses present a smoother and better correlation with SM than NBO/T (Fig. 6a and b). So, with this method, dissolved water can be estimated without necessarily standard glasses having exactly the same composition as the unknown sample. In order to minimise the $q$ term of Eq. (5) and obtain Eq. (10), $k$ value must be calibrated on absorbing glasses or at the depth of maximum signal intensity for transparent and semi transparent glasses. With this approach, the simple measurement of the height ratio between the main bands $\left(\mathrm{H}_{2} \mathrm{O}_{\mathrm{T}}, \mathrm{LF}\right.$ and $\left.\mathrm{HF}\right)$ of the unknown hydrous glass allows to calculate its water content.

\section{Conclusion}

The quantification of the effects of bulk composition, water content and iron oxidation states on the relative intensity of the main Raman bands allows a prediction of the compositional dependence of micro-Raman calibration for quantitative water analysis in natural glasses. The intensity ratio (height or area) of the main bands related to vibrations of the silicate network $(\mathrm{LF} / \mathrm{HF})$ decreases with depolymerisation degree along a polynomial trend as a function of $\mathrm{SM}$ and NBO/T (structural parameters). This variation, which is best illustrated by SM parameters, can be predicted in hydrous glasses via empirical expressions (Eqs. (8) and (9)).

The height of $\mathrm{H}_{2} \mathrm{O}_{\mathrm{T}}$ band linearly increases with dissolved water content on a single slope in all studied compositions and, in first approximation, can be used for semi-quantitative estimate of the water concentration. Our data support the hypothesis that the cross-section of the $\mathrm{H}_{2} \mathrm{O}_{\mathrm{T}}$ band is independent of the glass matrix composition. The height of this band must be measured at the sample surface in absorbing (mafic) or multi-phase (glass + crystals + bubbles) glasses and at increasing depth in semi-transparent and transparent (silicic) mono-phase glasses. Focusing errors and fluctuations of delivered laser energy significantly affect the precision of water measurement with external calibration.

Internal calibration based on the $\mathrm{H}_{2} \mathrm{O}_{\mathrm{T}}$ band area normalised to LF band is accurate for all compositions. LF calibrations based on band heights are considered accurate only for acid and intermediate glasses. The slope of internal calibration lines, when the $\mathrm{H}_{2} \mathrm{O}_{\mathrm{T}}$ band intensity (height and area) is normalised to that of the HF band, decreases with increasing glass depolymerisation (as defined by $\mathrm{NBO} / \mathrm{T}$ or $\mathrm{SM}$ ). Iron oxidation state has only a minor effect 
on mafic iron-rich samples like basalts from Etna and Stromboli. However, the effect of iron oxidation state cannot be ignored in moderately to highly polymerised glasses (e.g. andesites, pantellerites), in mafic glasses when the $\mathrm{Fe}^{3+} / \mathrm{Fe}_{\mathrm{T}}$ value varies by $>35 \%$ and in synthetic glasses where no competition between iron and another network former element occurs.

For a given spectrometer, the constant molar scattering power $(k)$ of bulk water and the modelling of the dependence of relative band height $\left(I_{\mathrm{LF}} / I_{\mathrm{HF}}\right)$ on bulk glass composition allow us to propose a new procedure to quantify the water content in natural glasses. Calculated water concentrations with this procedure are in good agreement with the expected values for reference glasses with a standard deviation of 0.06 in the water range $0.4-7 \mathrm{wt} \%$. Application of the proposed analytical procedure to the analysis of hydrous glasses with $\mathrm{H}_{2} \mathrm{O}_{\mathrm{T}}>7 \mathrm{wt} \%$ or highly depolymerised glasses $(\mathrm{NBO} / \mathrm{T}>1.2)$ requires the extension of the current calibrations.

\section{Acknowledgments}

This work represents part of the Ph.D. research of M. Mercier and was supported by ANR program ANR-06-CATT-012-01 VOLGASPEC. We are grateful to D. Laporte for providing the water-rich rhyolitic sample. The manuscript benefited of the careful reviews of R. Thomas, Z. Zajacz and of an anonymous reviewer and of the thoughtful handling of P. Ulmer. We thank B. Williamson for improving the English version of the paper.

\section{References}

Arias et al., 2006 A. Arias, M. Oddone, G. Bigazzi, A. Di Muro, C. Principe and P. Norelli, New data for the characterisation of Milos obsidians, J. Radioanal. Nuclear Chem. 268 (2006), pp. 371-386.

Arredondo and Rossman, 2002 E.H. Arredondo and G. Rossman, Feasibility of determining the quantitative $\mathrm{OH}$ content of garnets with Raman spectroscopy, Am. Mineral. 87 (2002), pp. $307-311$.

Behrens et al., 2006 H. Behrens, J. Roux, D.R. Neuville and M. Siemann, Quantification of dissolved $\mathrm{H}_{2} \mathrm{O}$ in silicate glasses using confocal micro-Raman spectroscopy, Chem. Geol. 229 (2006), pp. 96-112

Bell et al., 1970 R.J. Bell, P. Dean and D.C. Hibbins-Butler, Localization of normal modes in vitreous silica, germania and beryllium fluoride, J. Phys. C Solid State Phys. 3 (1970), pp. 2111-2118.

Bell and Dean, 1972 R.J. Bell and P. Dean, Structure of vitreous silica. Validity of the random network theory, Philos. Mag. 25 (1972), pp. 1381-1398.

Bonnin-Mosbah et al., 2002 M. Bonnin-Mosbah, N. Métrich, J. Susini, M. Salomé, D. Massare and B. Menez, Micro X-ray absorption near edge structure at the sulfur and iron Kedges in natural silicate glasses, Spectrochim. Acta 57 (2002), pp. 711-725.

Chabiron et al., 2004 A. Chabiron, J. Pironon and D. Massare, Characterization of water in synthetic rhyolitic glasses and natural melt inclusions by Raman spectroscopy, Contrib. Mineral. Petrol. 146 (2004), pp. 485-492. 
Cooney and Sharma, 1990 T.F. Cooney and S.K. Sharma, Structure of glasses in the system $\mathrm{Mg}_{2} \mathrm{SiO}_{4}-\mathrm{Fe}_{2} \mathrm{SiO}_{4}, \mathrm{Mn}_{2} \mathrm{SiO}_{4}-\mathrm{Fe}_{2} \mathrm{SiO}_{4}, \mathrm{Mg}_{2} \mathrm{SiO}_{4}-\mathrm{CaMgSiO}_{4}$ and $\mathrm{MnSiO}_{4}-\mathrm{CaMnSiO}_{4}$, J. NonCryst. Solids 122 (1990), pp. 10-32

Dingwell and Brearley, 1988 D.B. Dingwell and M. Brearley, Melt densities in the CaO$\mathrm{FeO}-\mathrm{Fe}_{2} \mathrm{O}_{3}-\mathrm{SiO}_{2}$ system and the compositional dependence of the partial molar volume of ferric iron in silicate melts, Geochim. Cosmochim. Acta 52 (1988), pp. 2815-2872.

Dingwell et al., 1988 D.B. Dingwell, M. Brearley and D. Virgo, The dual role of ferric iron in liquid silicates: effects on density \& viscosity, Chem. Geol. 70 (1988), p. 86.

Dingwell et al., 1996 D.B. Dingwell, C. Romano and K.U. Hess, The effect of water on the viscosity of a haplogranitic melt under $P-T-X$ conditions relevant to silicic volcanism, Contrib. Mineral. Petrol. 124 (1996), pp. 19-28.

Di Muro et al., 2004 A. Di Muro, A. Neri and M. Rosi, Contemporaneous convective and collapsing eruptive dynamics: the transitional regime of explosive eruptions, Geophys. Res. Lett. 31 (2004), p. L10607.

Di Muro et al., 2006a A. Di Muro, B. Villemant, G. Montagnac, B. Scaillet and B. Reynard, Quantification of water content and speciation in natural silicic glasses (phonolite, dacite, rhyolite) by confocal micro-Raman spectroscopy, Geochim. Cosmochim. Acta 70 (2006), pp. 2868-2884.

Di Muro et al., 2006b A. Di Muro, D. Giordano, B. Villemant, G. Montagnac, B. Scaillet and C. Romano, Influence of composition and thermal history of volcanic glasses on water content as determined by micro-Raman spectrometry, Appl. Geochem. 70 (2006), pp. 802812 .

Di Muro et al., 2008 A. Di Muro, N. Métrich, M. Mercier, G. Giordano, D. Massare and G. Montagnac, Micro-Raman Determination of Iron Redox State in Dry Natural Glasses: Application to Peralkaline Rhyolites and Basalts, Chem. Geol. (2008)

Faurskov Nielsen, 1996 O. Faurskov Nielsen, Low-frequency spectroscopic studies and intermolecular vibrational energy transfer in liquids, Annu. Rep. Prog. Chem. Sect. C Phys. Chem. (1996), pp. 57-99.

Furukawa et al., 1981 T. Furukawa, K.E. Fox and W.B. White, Raman spectroscopic investigation of the structure of silicate glasses. III. Raman intensities and structural units in sodium silicate glasses, J. Chem. Phys. 75 (1981), pp. 3226-3237.

F.L. Galeener, Planar rings in glasses, Solid State Comm. 44 (1982), pp. 1037-1040.

Galeener, 1982b F.L. Galeener, Planar rings in vitreous silica, J. Non-Cryst. Solids 49 (1982), pp. 53-62.

Giordano and Dingwell, 2003 D. Giordano and D.B. Dingwell, Non-Arrhenian multicomponent melt viscosity: a model, Earth Planet. Sci. Lett. 208 (2003), pp. 337-349. 
Giordano et al., 2004 D. Giordano, C. Romano, D.B. Dingwell, B. Poe and H. Behrens, The combined effects of water and fluorine on the viscosity of silicic magmas, Geochim.

Cosmochim. Acta 68 (2004), pp. 5159-5168.

Giordano et al., 2006 D. Giordano, A. Mangiacarpa, M. Potuzak, J.K. Russel, C. Romano, D.B. Dingwell and A. Di Muro, An expanded non-Arrhenian model for silicate melt viscosity, a treatment for metaluminous, peraluminous, and peralkaline liquids, Chem. Geol. 229 (2006), pp. 42-56.

Giordano et al., 2007 D. Giordano, P. Ardia, A. Mangiacapra, C. Romano, D.B. Dingwell, R. Cioni, M.W. Schmidt and K.U. Hess, The rheology of Vesuvius magmas, Geophys. Res. Abs. 9 (2007), p. 04796.

Giordano et al., 2008 D. Giordano, J.K. Russel and D.B. Dingwell, Viscosity of magmatic liquids: a model, Earth Planet. Sci. Lett. 271 (2008), pp. 123-134.

Kushiro, 1982 I. Kushiro, Density of tholeiite and alkali basalt magmas at high pressure, Carnegie Inst. Washington Year Book 82 (1982), pp. 305-309.

Lange and Carmichael, 1990 Lange R. and Carmichael I. S. E. (1990) Thermodynamics properties of silicate liquids with emphasis on density, thermal expansion and compressibility. In Understanding Magmatic Processes. Modern Methods of Igneous Petrology. Rev. Mineral. (eds. J. Nicholls and J. K. Russel), vol. 24, pp. 25-64.

Lesne et al., submitted for publication Lesne P., Scaillet B., Pichavant M., Iacono-Marziano G. and Beny J. M. (submitted for publication) The water solubility in alkali basalts from Italy: an experimental study. Contrib. Mineral. Petrol..

Linnen, 2005 R. Linnen, The effect of water on accessory phase solubility in subaluminous and peralkaline granitic melts, Lithos 80 (2005), pp. 267-280.

Litasov and Ohtani, $2007 \mathrm{~K}$. Litasov and E. Ohtani, Effect of water on the phase relations in Earth's mantle and deep water cycle, Geol. Soc. Amer. Spec. Paper (2007), p. 421.

Long, 1977 D.A. Long, Raman Spectroscopy, McGraw-Hill, Inc., Great Britain (1977) 275 p.

Magnien et al., 2006 V. Magnien, D.R. Neuville, L. Cormier, J. Roux, J.-L. Hazemann, O. Pinet and P. Richet, Kinetics of iron redox reactions in silicate liquids, a high-temperature Xray absorption and Raman spectroscopy study, J. Nuc. Mat. 352 (2006), pp. 190-195.

Matson et al., 1983 D.W. Matson, S.K. Sharma and J.A. Philpotts, The structure of high-silica alkali silicate glasses. A Raman spectroscopic investigation, J. Non-Cryst. Solids 58 (1983), pp. 323-352.

McMillan, 1984 P.F. McMillan, Structural studies of silicate glasses and melts, applications and limitations of Raman spectroscopy, Am. Mineral. 69 (1984), pp. 622-644.

McMillan and Remmele, 1986 P.F. McMillan and R.L. Remmele, Hydroxyl sites in $\mathrm{SiO}_{2}$ glass, a note on infrared and Raman spectra, Am. Mineral. 71 (1986), pp. 772-778. 
McMillan et al., 1995 P.F. McMillan, B.T. Poe, P. Gillet and B. Reynard, A study of $\mathrm{SiO}_{2}$ glass and supercooled liquid to $1950 \mathrm{~K}$ via high-temperature Raman spectroscopy, Geochim. Cosmochim. Acta 58 (1995), pp. 3653-3664.

Mourtada-Bonnefoi and Laporte, 2004 C.C. Mourtada-Bonnefoi and D. Laporte, Kinetics of bubble nucleation in a rhyolitic melt, an experimental study of the effect of ascent rate, Earth Planet. Sci. Lett. 218 (2004), pp. 521-537.

Mysen and Virgo, 1980 B.O. Mysen and D. Virgo, Solubility mechanisms of water in basalt melt at high pressures and temperatures: $\mathrm{NaCaAlSi}_{2} \mathrm{O}_{7} \cdot \mathrm{H}_{2} \mathrm{O}$ as a model, Am. Mineral. 65 (1980), pp. 1176-1184.

Mysen et al., 1980a B.O. Mysen, D. Virgo, W.J. Harrison and C.M. Scarfe, Solubility mechanisms of $\mathrm{H}_{2} \mathrm{O}$ in silicate melts at high pressures and temperatures, a Raman spectroscopic study, Am. Mineral. 65 (1980), pp. 900-914.

Mysen et al., 1980b B.O. Mysen, F.A. Seifert and D. Virgo, Structure and redox equilibria of iron-bearing silicate melts, Am. Mineral. 65 (1980), pp. 867-884.

Mysen, 1988 B.O. Mysen, Structure and Properties of Silicate Melts, Elsevier, Amsterdam (1988).

Mysen et al., 1997 B.O. Mysen, F. Holtz, M. Pichavant, J.M. Beny and J.M. Montel, Solution mechanisms of phosphorous in quenched hydrous and anhydrous granitic glass as a function of peraluminosity, Geochim. Cosmochim. Acta 61 (1997), pp. 3913-3926

Mysen, 1999 B.O. Mysen, Structure and properties of magmatic liquids, from haplobasalt to haploandesite, Geochim. Cosmochim. Acta 63 (1999), pp. 95-112

Mysen, 2007 B.O. Mysen, The solution behavior of $\mathrm{H}_{2} \mathrm{O}$ in peralkaline aluminosilicate melts at high pressure with implications for properties of hydrous melts, Geochim. Cosmochim. Acta 71 (2007), pp. 1820-1834.

Pandya et al., 1992 N. Pandya, D.W. Muenow and K.S. Shiv, The effect of bulk composition on the speciation of water in submarine volcanic glasses, Geochim. Cosmochim. Acta $\mathbf{5 6}$ (1992), pp. 1875-1883.

Pasquarello and Car, 1998 A. Pasquarello and R. Car, Identification of Raman defect lines as signatures of ring structures in vitreous silica, Phys. Rev. Lett. 80 (1998), pp. 5145-5147.

Persikov et al., 1990 E.S. Persikov, P.G. Zharikov and S.F. Polskoy, The effects of volatiles on the properties of magmatic melts, Eur. J. Miner. 2 (1990), pp. 621-642.

Pichavant et al., 2002 M. Pichavant, B.O. Mysen and R. MacDonald, Source and $\mathrm{H}_{2} \mathrm{O}$ content of high-MgO magmas in island arc settings, an experimental study of primitive calc-alkaline basalt from St. Vincent, Lesser Antilles arc, Geochim. Cosmochim. Acta 12 (2002), pp. 2193 2209.

Richet et al., 1996 P. Richet, A.-M. Lejeune, F. Holtz and J. Roux, Water and the viscosity of andesite melts, Chem. Geol. 128 (1996), pp. 185-197. 
Richet et al., 2000 P. Richet, A. Whittington, F. Holtz, H. Behrens, S. Ohlhorst and M. Wilke, Water and the density of silicate glasses, Contrib. Mineral. Petrol. 138 (2000), pp. 337-347.

Robert et al., 2008 G. Robert, J.K. Russell, D. Giordano and C. Romano, High-T deformation of volcanic materials in the presence of water, Am. Mineral. 93 (2008), pp. 74-80.

Scaillet and Evans, 1999 B. Scaillet and B.W. Evans, The 15 June 1991 eruption of Mont Pinatubo. I. Phase equilibria and pre-eruption $P-T-f \mathrm{O}_{2}-f \mathrm{H}_{2} \mathrm{O}$ conditions of the dacite magma, J. Petrol. 40 (1999), pp. 381-411.

Scaillet and Pichavant, 2004 B. Scaillet and M. Pichavant, Crystallization conditions of Vesuvius phonolites, Geophys. Res. Abs. 6 (2004), p. 03764.

Severs et al., 2007 M.J. Severs, T. Azbej, J.B. Thomas, C.W. Mandeville and R.J. Bodnar, Experimental determination of $\mathrm{H}_{2} \mathrm{O}$ loss from melt inclusions during laboratory heating: evidence from Raman spectroscopy, Chem. Geol. 237 (2007), pp. 358-371.

Sharma et al., 1981 S.K. Sharma, J.F. Mammone and M.F. Nicol, Ring configurations in vitreous silica — a Raman spectroscopic investigation, Nature 292 (1981), pp. 140-141.

Sharma et al., 1983 S.K. Sharma, B. Simons and H.S. Yoder, Raman study of anorthite, calcium Tschermak's pyroxene and gehlenite in crystalline and glassy states, Am. Mineral. (1983), pp. 1113-1125.

Sharma et al., 1997 S.K. Sharma, T.F. Cooney, Z. Wang and S. Van Der Lan, Raman band assignment of silicate and germanate glasses using high-pressure and high-temperature spectral data, J. Raman Spectrosc. 28 (1997), pp. 697-709.

Spilliaert et al., 2006 N. Spilliaert, P. Allard, N. Métrich and A.V. Sobolev, Melt inclusion record of the conditions of ascent, degassing and extrusion of volatile-rich alkali basalt during the powerful 2002 flank eruption of Mount Etna (Italy), J. Geophys. Res. 111 (2006), p. BO4203

Stolen and Walrafen, 1976 R.H. Stolen and G.E. Walrafen, Water and its relation to broken bond defects in fused silica, J. Chem. Phys. 64 (1976), pp. 2623-2631.

Stolper, 1982 E. Stolper, Water in silicate glasses, an infrared spectroscopic study, Contrib. Mineral. Petrol. 81 (1982), pp. 1-17.

Thomas, 2000 R. Thomas, Determination of water contents of granite melt inclusions by confocal laser Raman microprobe spectroscopy, Am. Mineral. 85 (2000), pp. 868-872.

Thomas et al., 2008a S.M. Thomas, R. Thomas, P. Davidson, P. Reichart, M. Koch-Müller and G. Dollinger, Application of Raman spectroscopy to quantify trace water concentration in glasses and garnets, Am. Mineral. 93 (2008), pp. 1550-1557.

Thomas et al., 2008b R. Thomas, N. Métrich, B. Scaillet, V. Kamenetsky and P. Davidson, Determination of water in Fe-rich basalt glasses with confocal micro-Raman spectroscopy, $Z$. Geol. Wiss. 36 (2008), pp. 31-37. 
Wang et al., 1995 Z. Wang, T.F. Cooney and S.K. Sharma, In situ structural investigation of iron containing silicate liquids and glasses, Geochim. Cosmochim. Acta 59 (1995), pp. 15711577.

Whittington et al., 2000 A. Whittington, P. Richet and F. Holtz, Water and the viscosity of depolymerized aluminosilicate melts, Geochim. Cosmochim. Acta 64 (2000), pp. 3725-3736.

Zajacz et al., 2005 Z. Zajacz, W. Halter, W.J. Malfait, O. Bachmann, R.J. Bodnar, M.M. Hirschmann, C.W. Mandeville, Y. Morizet, O. Muntener, P. Ulmer and J.D. Webster, A composition-independent quantitative determination of the water content in silicate glasses and silicate melt inclusions by confocal Raman spectroscopy, Contrib. Mineral. Petrol. 150 (2005), pp. 631-642.

Zotov and Keppler, 1998 N. Zotov and H. Keppler, The influence of water on the structure of hydrous sodium tetrasilicate glasses, Am. Mineral. 83 (1998), pp. 823-834. 


\section{Figures}
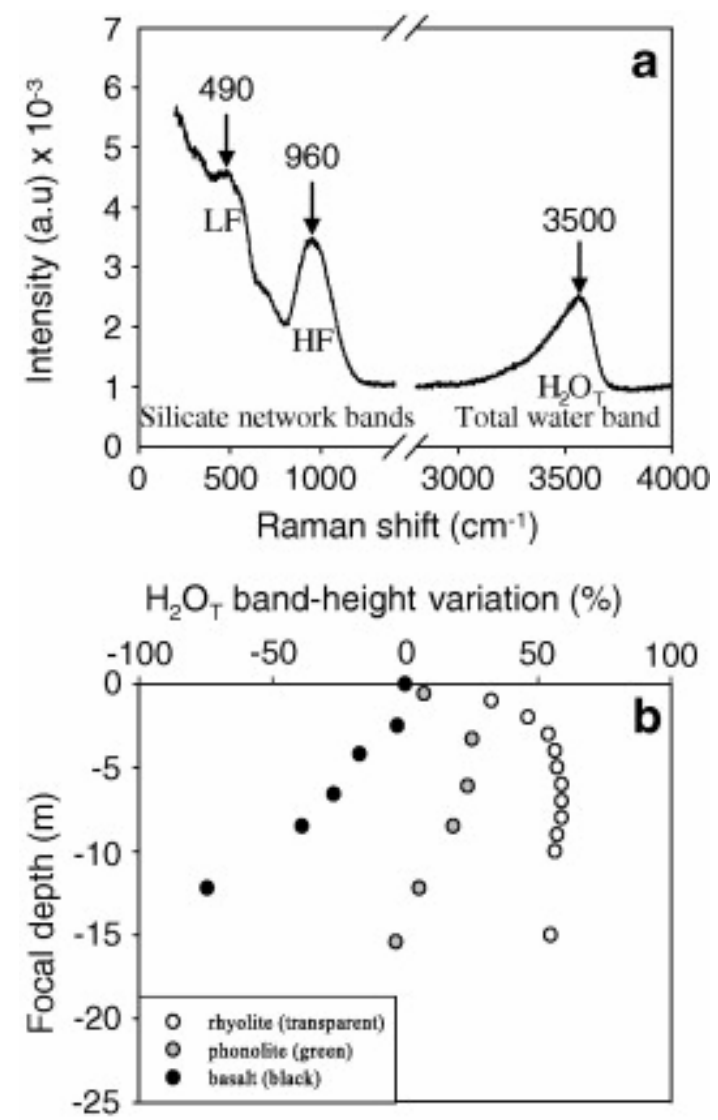

Fig. 1. (a) Main Raman bands in the uncorrected and unpolarised spectrum of highly depolymerised basanitic glass (from La Sommata, Vulcano Island) containing $4.95 \mathrm{wt} \%$ water. (b) Influence of glass absorptivity and focusing depth of the laser beam on the height of the $\mathrm{H}_{2} \mathrm{O}_{\mathrm{T}}$ band. Maximum signal intensity moves from a depth of 5-8 $\mu \mathrm{m}$ in colourless, iron-poor glasses (rhyolite) to the sample surface in highly absorbing iron-rich glasses (basalt). Depth of maximum signal intensity depends on confocality degree of the analytical system. 


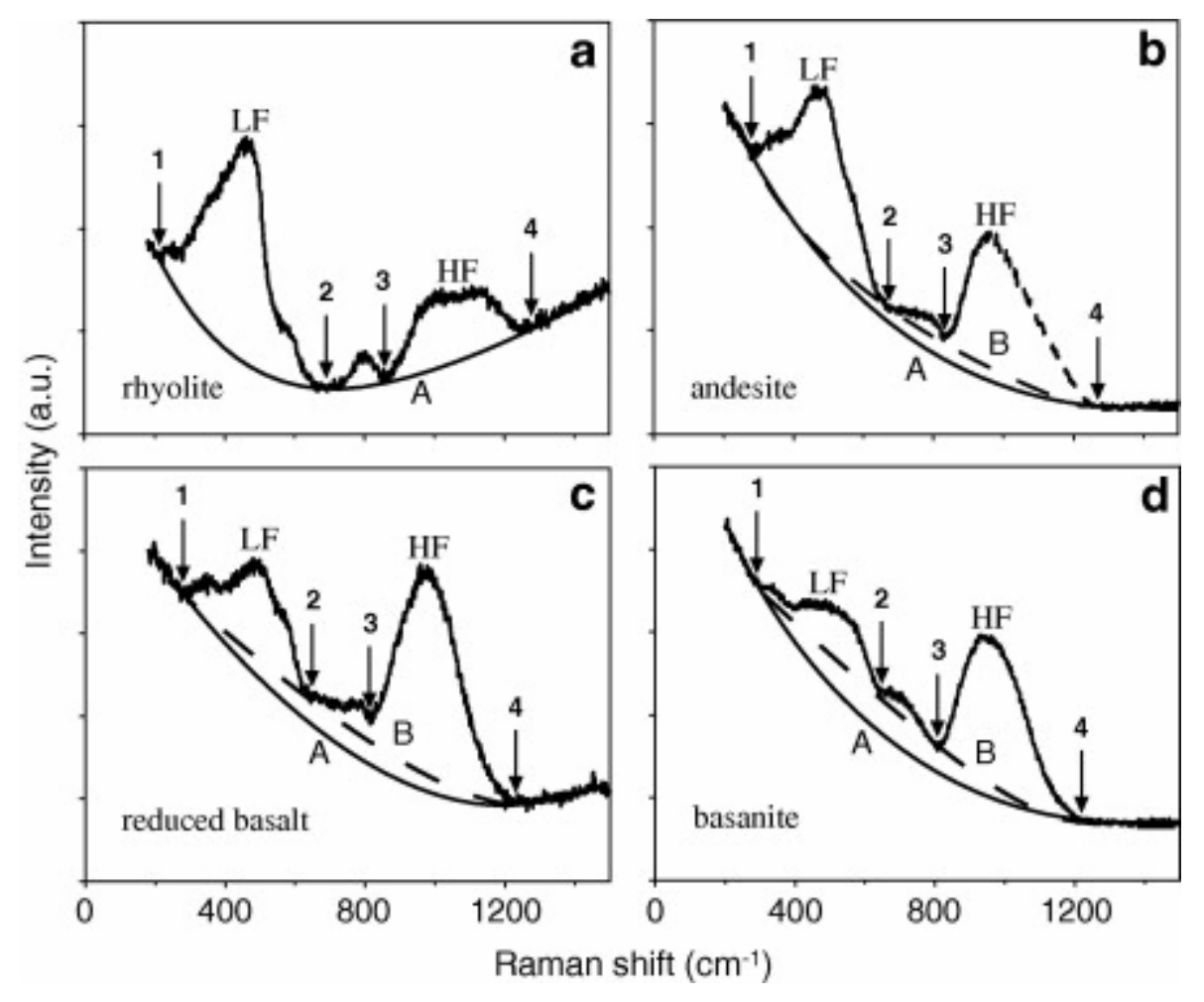

Fig. 2. Uncorrected Raman spectra of (a) Newberry rhyolite, (b) Montserrat andesite, (c) Stromboli reduced basalt $\left(\mathrm{Fe}^{3+} / \mathrm{Fe}_{\mathrm{T}}=0.05\right)$ and (d) Sommata basanite. Solid baseline represents the cubic baseline A fitted to the spectra extremities. The dashed baseline represents the cubic B fitted to points 1,2 and 4. Point 3 is commonly fitted when linear baselines are adopted. 


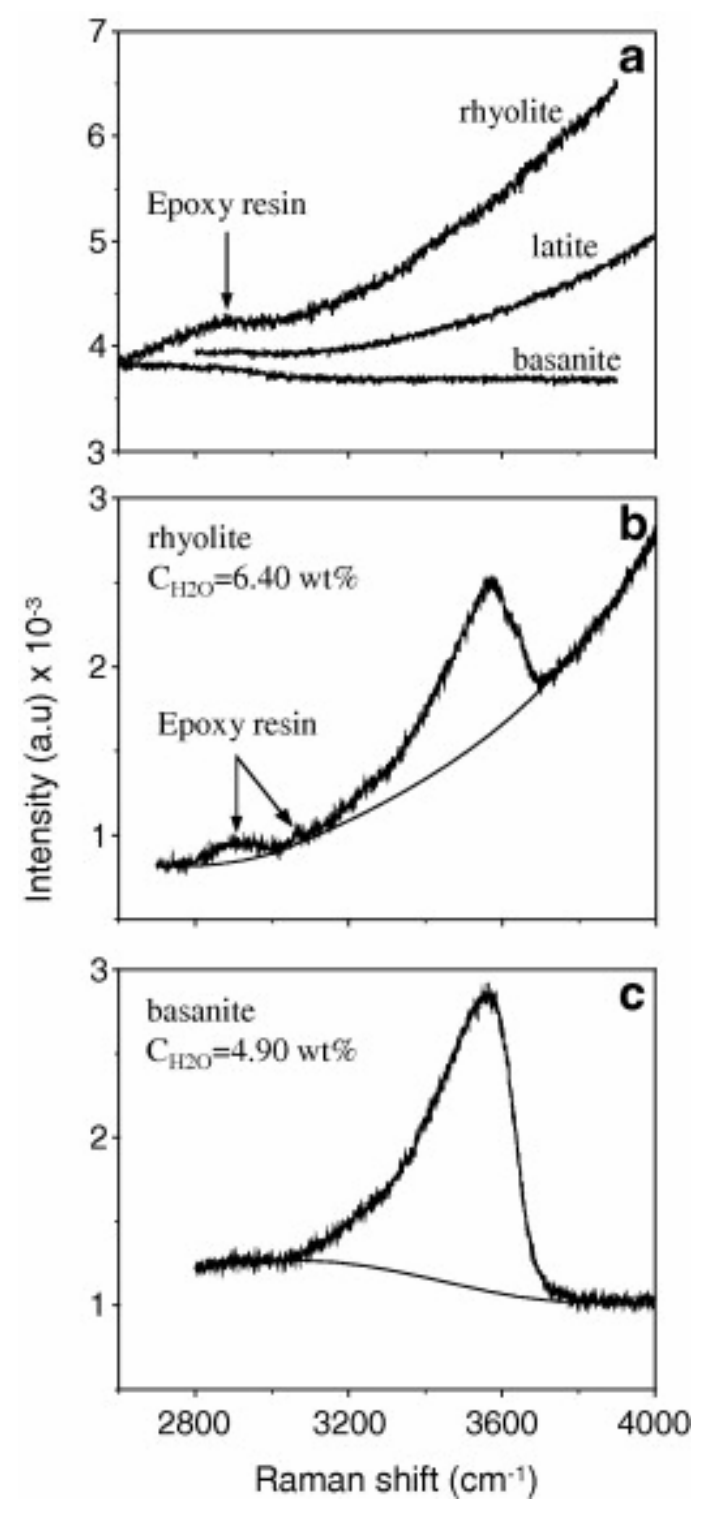

Fig. 3. (a) Raman spectra of dry glass samples with decreasing transparency from rhyolite to basanite. Fluorescence backgrounds are produced by the excitation of embedding resin and are best fitted by a cubic baseline. Comparison between uncorrected Raman spectra with the appropriate baseline correction for (b) a metaluminous rhyolite glass with $6.40 \mathrm{wt} \%$ of water content and (c) a basanitic Sommata glass with $4.90 \mathrm{wt} \%$ of water content demonstrates that a linear baseline approximate the background only in dark mafic glasses. All the absolute intensities have been divided by 1000 . 


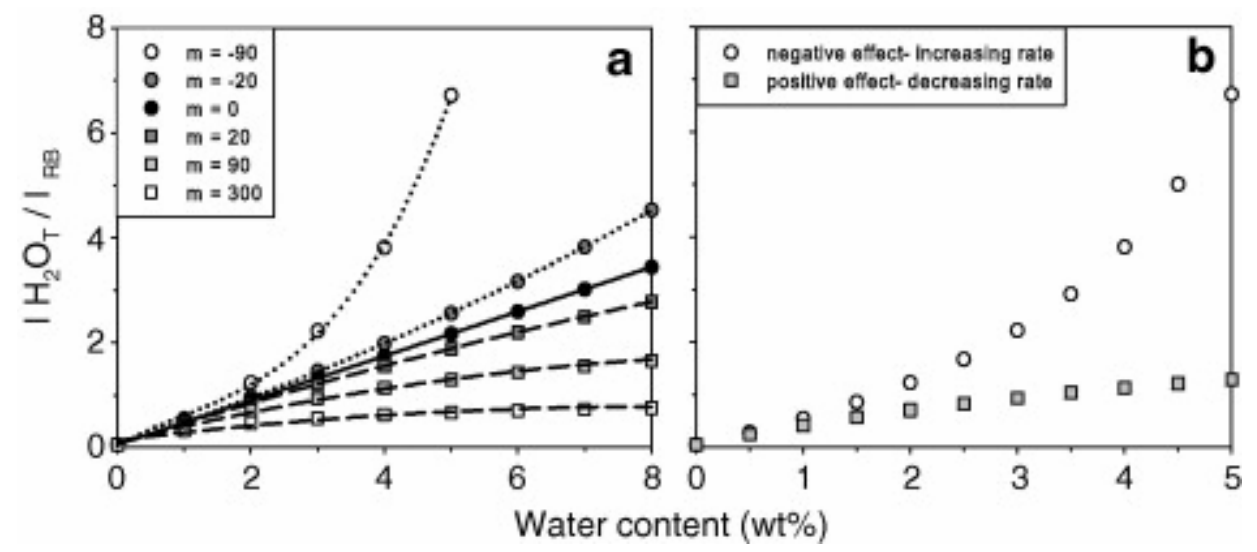

Fig. 4. Variation in the height of the $\mathrm{H}_{2} \mathrm{O}_{\mathrm{T}}$ band normalised to the height of a reference band (RB) with variable sensitivity $(m)$ to the dissolved water content as defined by Eq. (3). (a) The solid line represents calibration with no water effect on glass structure and thus on height of the reference band. The other curves show the respective effect of the linear increase (dashed) or decrease (dotted) of the reference band intensity with increasing water content. Sensitivity of reference bands often changes with large variations in water content. The combined positive and negative effects on $I_{\mathrm{RB}}$ have been compared in the plot (b) with $m$ value of 90 and -90. The parameters $k$ and $q$ correspond to those measured in our most depolymerised glass set (Sommata basanite) where

is the intensity of the water-poor basanite samples $(0.79 \mathrm{wt} \%)$. 
Dry glasses
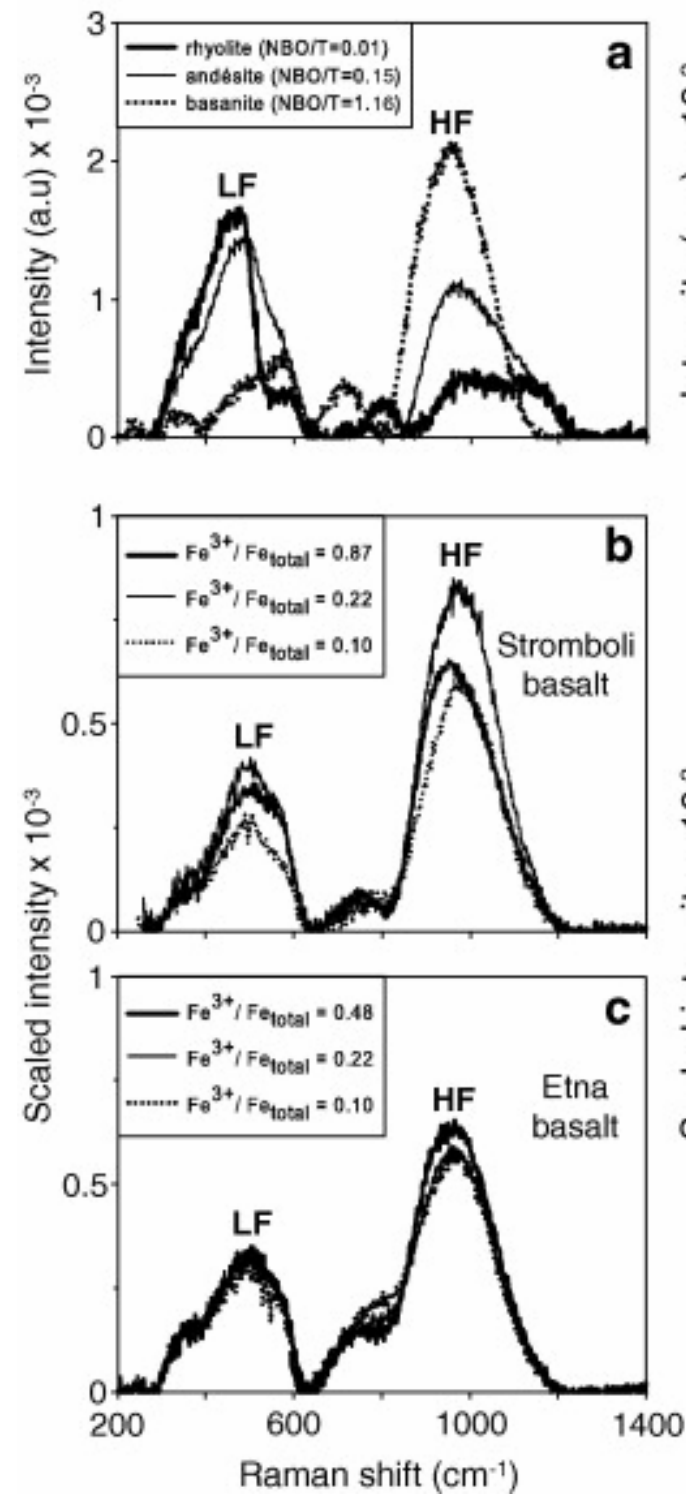

Hydrous glasses
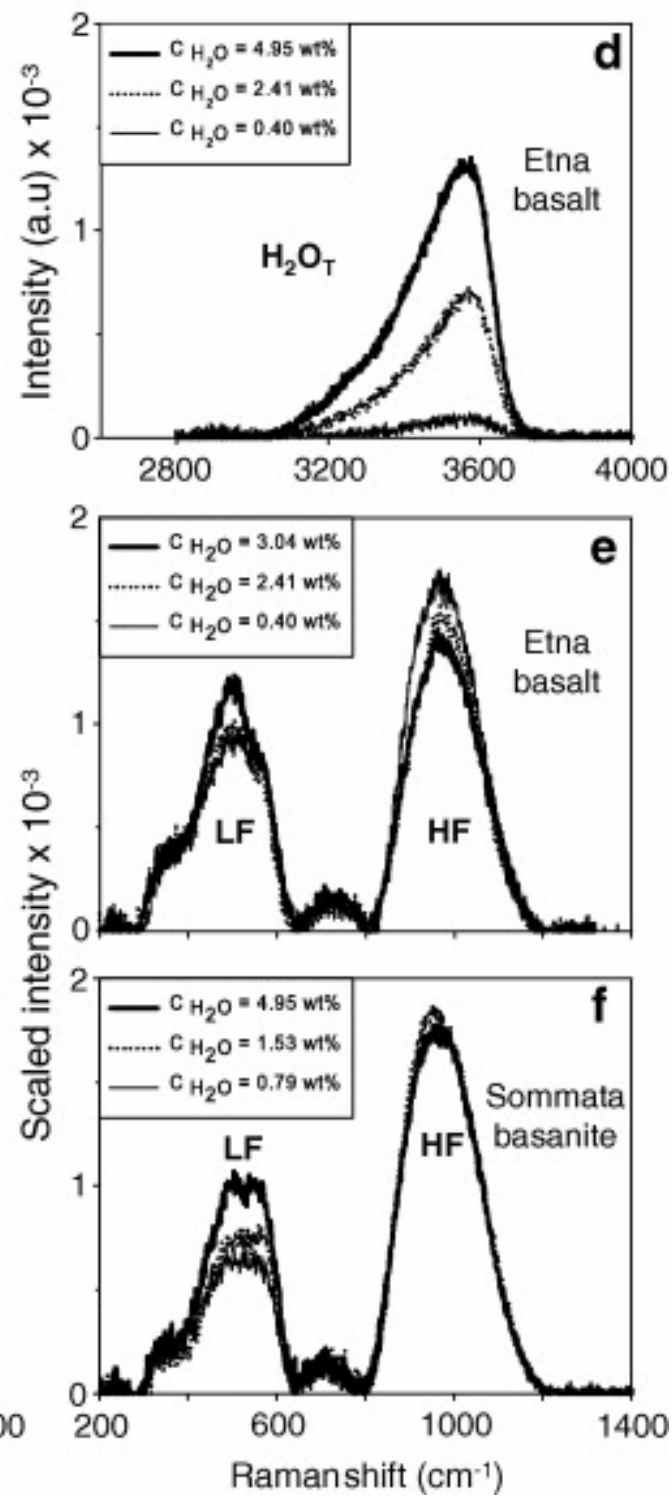

Fig. 5. Unpolarised Raman spectra of anhydrous and hydrous glasses after subtraction of the cubic B baseline. Raman spectra of anhydrous glasses including (a) Rattlesnake metaluminous rhyolite, Montserrat andesite, and Eifel basanite. Raman spectra of anhydrous glasses with variable iron oxidation state from (b) Stromboli and (c) Etna basalts, respectively. High frequency Raman spectra of Etna water-bearing basalts (d). Low frequency Raman spectra of water-bearing Etna basalts (e) and Sommata basanite (f) with increasing water content. Minor intensity fluctuations due to focusing errors are corrected by normalising the intensity of LF and HF bands to the intermediate region $\left(\sim 700 \mathrm{~cm}^{-1}\right)$ whose intensity mainly depends on glass silica content. 

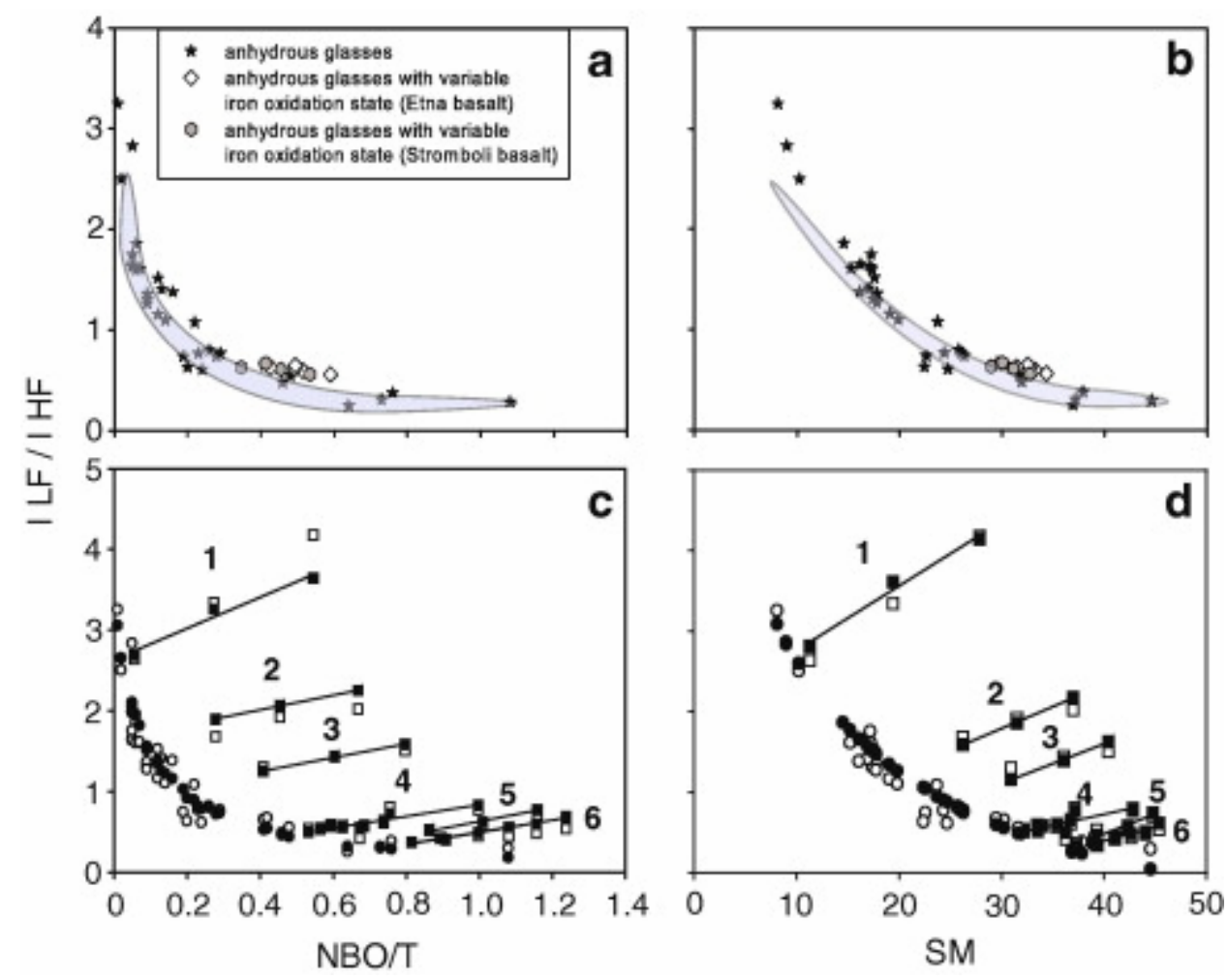

Fig. 6. Measured variation of height (symbols) and area (shadowed area) ratios of the two main bands related to vibration of the glass network (LF, low frequency; HF, high frequency), as a function of glass polymerisation expressed as (a) NBO/T (non-bridging oxygen per tetrahedron) and (b) SM (sum of network modifiers) in natural anhydrous glasses.

Comparison between calculated (filled symbols) and measured (open symbols) $I_{\mathrm{LF}} / I_{\mathrm{HF}}$ ratio vs. (c) NBO/T and (d) SM parameters. Numbers in the plots (c) and (d) refer to the set of hydrous glasses: (1) rhyolite; (2) Pompeï iron-poor phonolite; (3) Pollena iron-rich phonolite; (4) Etna basalt; (5) Vesuvius tephrite; (6) Sommata basanite. Note that the wavenumber, at which the height of LF and HF bands are measured, shifts with bulk glass composition and water content. 


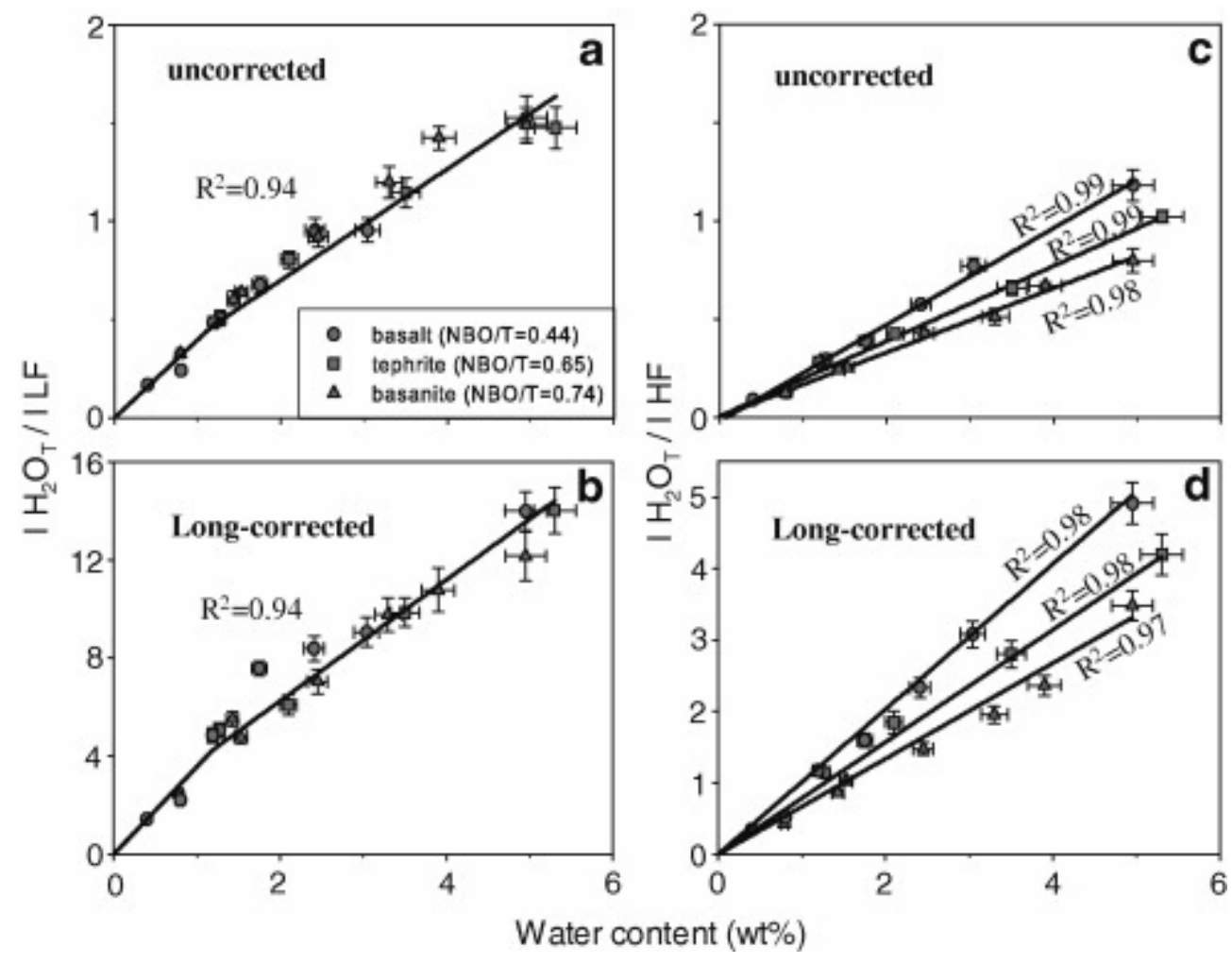

Fig. 7. Internal calibration lines for water analysis in mafic glasses using LF and HF as reference bands for uncorrected spectra (a and c) and Long-corrected spectra (b and d). $\underline{I}_{\mathrm{H} 2 \mathrm{OT}}$, $I_{\mathrm{LF}}$ and $I_{\mathrm{HF}}$ values correspond to the height of main Raman bands. Note the very different scales of the plots of uncorrected and Long-corrected data. These latter give rises to much steeper slopes compared to uncorrected data. 

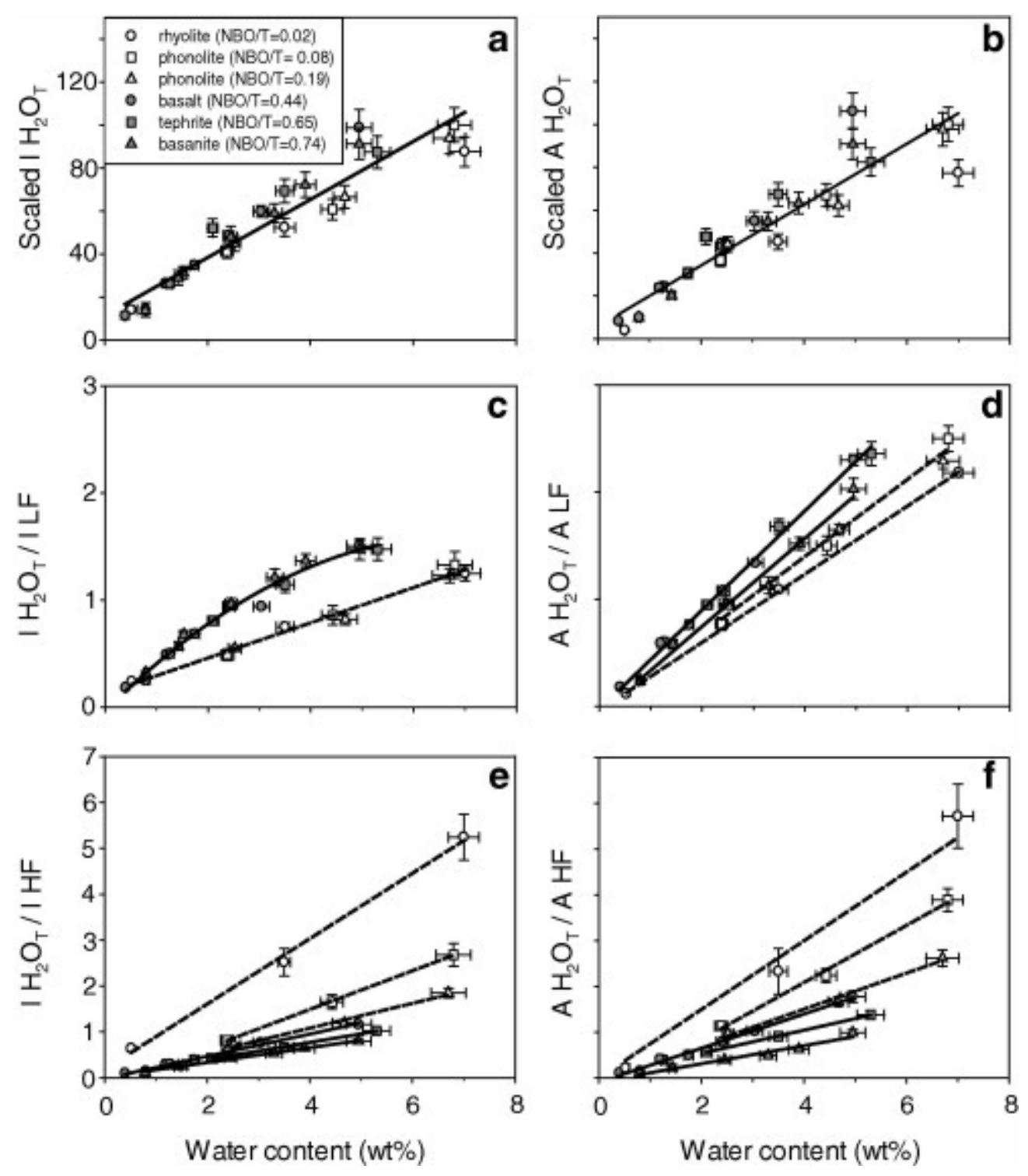

Fig. 8. External calibrations for Raman water analysis on the basis of the absolute measurements of height $\underline{I}_{\mathrm{H} 2 \mathrm{O}}$ (a) and area $\underline{A}_{\mathrm{H} 2 \mathrm{O}}$ of the total water band (b). Internal calibration based on the normalised $\mathrm{H}_{2} \mathrm{O}_{\mathrm{T}}$ band to the height (c) and area (d) of LF band. Internal calibration based on the normalised $\mathrm{H}_{2} \mathrm{O}_{\mathrm{T}}$ band to the height (e) and area (f) of HF band. In the plots (a) and (b), the intensities were normalised to the maximum value of the measured intensity $\left(\underline{I_{\mathrm{H} 2 \mathrm{OT}}}\right)$ in Pompeï phonolitic set (Table 2$)$ during repeated measurements. 

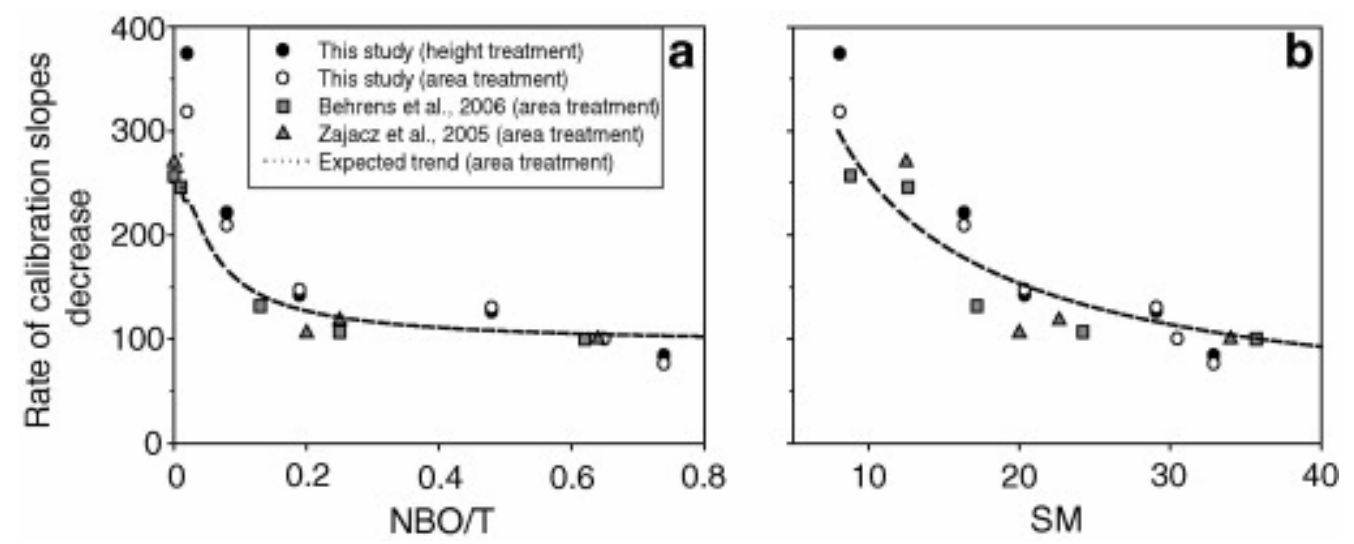

Fig. 9. Evolution of slopes of HF calibration lines based on the normalised areas of $\underline{A}_{\mathrm{H} 2 \mathrm{O}}$ $\left(\sim 3550 \mathrm{~cm}^{-1}\right)$ and HF band $\left(\sim 960 \mathrm{~cm}^{-1}\right)$ vs. NBO/T (a) and SM (b) parameters. The expected trend (dotted curve) is modelled using the Eqs. (1), (6) and (7) calibrated on the studied set of glass standards with an area treatment. For comparison each set of measurement has been scaled to values obtained on glasses with approximately the same NBO/T $(\sim 0.62)$.

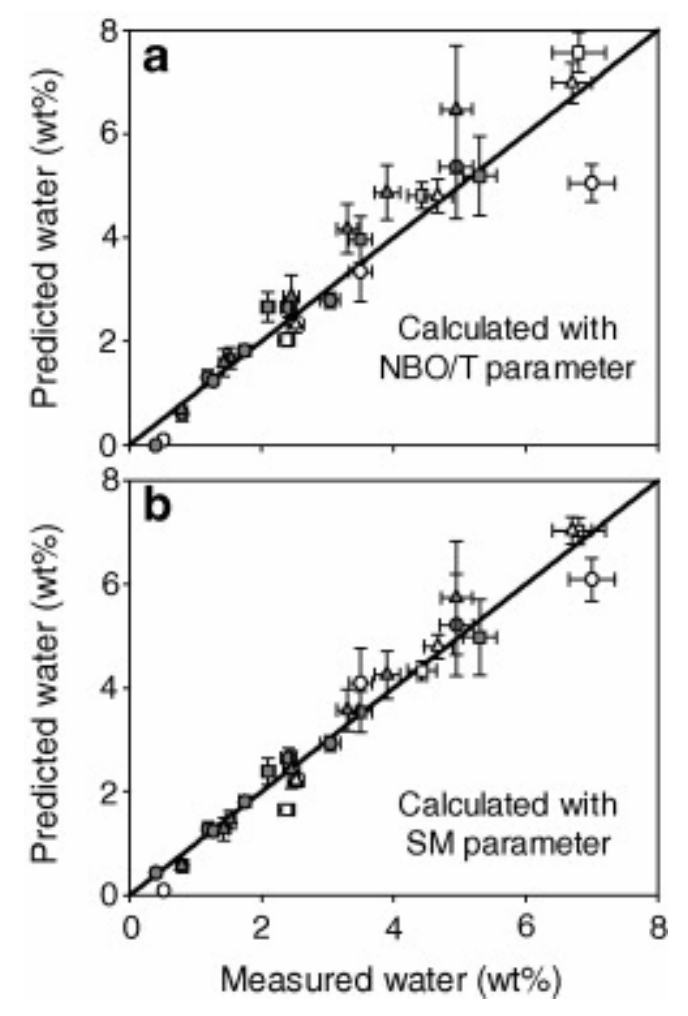

Fig. 10. Comparison between the dissolved water concentrations calculated through our general Eq. (5) and measured on bulk glass fragments using KFT, as a function of NBO/T (a) and SM (b). Symbols as in Fig. 8. 



\section{Table 1a. :}

Compositions (EPMA), synthesis conditions and height ratios of measured Raman bands related to vibration of alumino-silicate network (LF, HF) for anhydrous glasses.

\begin{tabular}{|c|c|c|c|c|c|c|c|c|c|c|c|c|c|c|c|c|c|}
\hline Location & Sample & Composition & $\mathrm{SiO}_{2}$ & $\begin{array}{l}\text { TiO } \\
2\end{array}$ & $\begin{array}{l}\mathrm{Al}_{2} \mathrm{O} \\
3\end{array}$ & $\begin{array}{l}\mathrm{FeO}_{\mathrm{t}} \\
\text { ot }\end{array}$ & $\begin{array}{l}\text { Mn } \\
\text { O }\end{array}$ & $\begin{array}{l}\text { Mg } \\
\text { O }\end{array}$ & $\begin{array}{l}\text { Ca } \\
\mathbf{O}\end{array}$ & $\begin{array}{l}\mathrm{Na}_{2} \\
\mathrm{O}\end{array}$ & $\mathrm{K}_{2} \mathrm{O}$ & $\begin{array}{l}\mathrm{P}_{2} \mathrm{O} \\
5\end{array}$ & Total & $\begin{array}{l}\mathbf{N B O} / \\
\mathbf{T}^{\mathbf{a}}\end{array}$ & $\underset{\mathbf{b}}{\mathbf{S M}}$ & $\begin{array}{l}\text { ILF/IH } \\
\mathbf{F}^{\mathbf{c}}\end{array}$ & $\underset{d}{\text { Ref. }}$ \\
\hline $\begin{array}{l}\text { Rattlesna } \\
\text { ke }\end{array}$ & RTF & $\begin{array}{l}\text { Metal. } \\
\text { rhyolite }\end{array}$ & $\begin{array}{l}76.2 \\
9\end{array}$ & 0.14 & $\begin{array}{l}12.0 \\
3\end{array}$ & 1.36 & 0.07 & 0.03 & 0.30 & 3.39 & 4.88 & 0.01 & 98.55 & 0.00 & 8.1 & 3.25 & 1 \\
\hline $\begin{array}{l}\text { New } \\
\text { Berry }\end{array}$ & NWB & $\begin{array}{l}\text { Metal. } \\
\text { rhyolite }\end{array}$ & $\begin{array}{l}73.2 \\
0\end{array}$ & 0.22 & $\begin{array}{l}13.9 \\
0\end{array}$ & 2.14 & 0.06 & 0.16 & 0.86 & 4.84 & 3.98 & 0.01 & 99.49 & 0.02 & $\begin{array}{l}10 . \\
2\end{array}$ & 2.50 & \# \\
\hline $\begin{array}{l}\text { Phlegrean } \\
\text { Field }\end{array}$ & $\mathrm{MN}$ & Trachyte & $\begin{array}{l}59.9 \\
2\end{array}$ & 0.42 & 19.4 & 3.07 & 0.22 & 0.26 & 1.69 & 5.82 & 7.30 & 0.01 & 98.38 & 0.05 & $\begin{array}{l}16 . \\
1\end{array}$ & 1.65 & 3 \\
\hline Vesuvius & $\begin{array}{l}\text { Mer } \\
1500\end{array}$ & Phonolite & $\begin{array}{l}58.8 \\
9\end{array}$ & 0.11 & $\begin{array}{l}20.5 \\
8\end{array}$ & 2.00 & 0.18 & 0.06 & 1.68 & 7.90 & 6.65 & 0.04 & 98.40 & 0.06 & $\begin{array}{l}17 . \\
0\end{array}$ & 1.63 & 4 \\
\hline Açores & PVC & Trachyte & $\begin{array}{l}65.2 \\
6\end{array}$ & 0.45 & $\begin{array}{l}17.3 \\
0\end{array}$ & 2.60 & 0.14 & 0.32 & 0.85 & 6.46 & 6.52 & 0.09 & $\begin{array}{l}100.0 \\
1\end{array}$ & 0.06 & $\begin{array}{l}14 . \\
5\end{array}$ & 1.86 & 3 \\
\hline Phlegrean & $\mathrm{MNV}$ & Trachyte & 63.8 & 0.31 & 17.1 & 2.90 & 0.13 & 0.24 & 1.82 & 5.67 & 6.82 & 0.05 & 99.09 & 0.07 & 15. & 1.61 & 3 \\
\hline
\end{tabular}




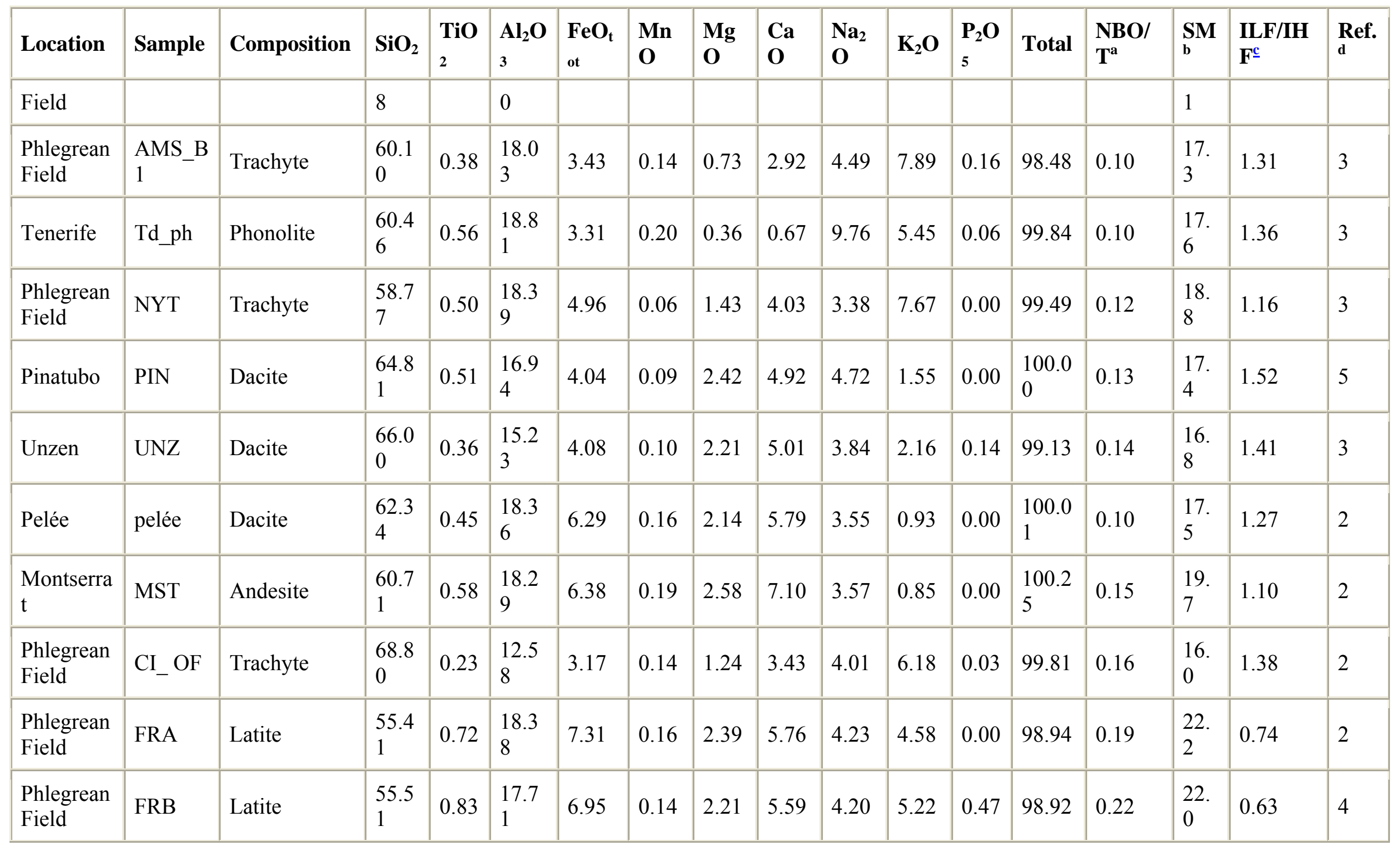




\begin{tabular}{|c|c|c|c|c|c|c|c|c|c|c|c|c|c|c|c|c|c|}
\hline Location & Sample & Composition & $\mathrm{SiO}_{2}$ & \begin{tabular}{|l} 
TiO \\
2 \\
\end{tabular} & $\begin{array}{l}\mathrm{Al}_{2} \mathrm{O} \\
3 \\
\end{array}$ & $\begin{array}{l}\mathrm{FeO}_{\mathrm{t}} \\
\text { ot }\end{array}$ & $\begin{array}{l}\text { Mn } \\
\mathbf{O}\end{array}$ & $\begin{array}{l}\text { Mg } \\
\text { O }\end{array}$ & $\begin{array}{l}\text { Ca } \\
\mathbf{O}\end{array}$ & $\begin{array}{l}\mathrm{Na}_{2} \\
\mathrm{O}\end{array}$ & $\mathbf{K}_{2} \mathbf{O}$ & $\begin{array}{l}\mathbf{P}_{2} \mathbf{O} \\
5\end{array}$ & Total & $\begin{array}{l}\mathbf{N B O} / \\
\mathbf{T}^{\mathbf{a}}\end{array}$ & $\underset{\mathbf{b}}{\mathbf{S M}}$ & $\begin{array}{l}\text { ILF/IH } \\
\mathbf{F}^{\mathbf{c}}\end{array}$ & $\underset{d}{\text { Ref. }}$ \\
\hline Vesuvius & POMP & Phonolite & $\begin{array}{l}53.8 \\
9\end{array}$ & 0.50 & $\begin{array}{l}18.9 \\
4\end{array}$ & 4.20 & 0.14 & 1.86 & 5.77 & 4.58 & 8.42 & 0.20 & 98.78 & 0.23 & $\begin{array}{l}23 . \\
5\end{array}$ & 1.08 & 4 \\
\hline Merapi & MRP & Andesite & $\begin{array}{l}53.5 \\
3\end{array}$ & 0.82 & $\begin{array}{l}18.9 \\
5\end{array}$ & 9.03 & 0.19 & 3.42 & 9.23 & 3.45 & 1.64 & 0.00 & $\begin{array}{l}100.2 \\
6\end{array}$ & 0.26 & $\begin{array}{l}25 . \\
2\end{array}$ & 0.80 & 2 \\
\hline Vesuvius & Ves G & Phonolite & $\begin{array}{l}51.2 \\
4\end{array}$ & 0.58 & $\begin{array}{l}19.1 \\
4\end{array}$ & 4.55 & 0.12 & 1.71 & 6.51 & 4.60 & 7.99 & 0.71 & 97.15 & 0.27 & $\begin{array}{l}24 . \\
4\end{array}$ & 0.61 & 3 \\
\hline $\begin{array}{l}\text { Phlegrean } \\
\text { Field }\end{array}$ & $\operatorname{Min} 2 b$ & Shoshonite & $\begin{array}{l}53.7 \\
2\end{array}$ & 0.64 & $\begin{array}{l}17.4 \\
7\end{array}$ & 7.22 & 0.17 & 3.78 & 8.07 & 3.63 & 3.53 & 0.00 & 98.23 & 0.30 & $\begin{array}{l}25 . \\
6\end{array}$ & 0.77 & 3 \\
\hline $\begin{array}{l}\text { Phlegrean } \\
\text { Field }\end{array}$ & $\operatorname{Min} 2 \mathrm{a}$ & Shoshonite & $\begin{array}{l}52.2 \\
6\end{array}$ & 0.75 & $\begin{array}{l}16.0 \\
6\end{array}$ & 7.45 & 0.10 & 5.56 & 9.92 & 2.33 & 3.67 & 0.00 & 98.10 & 0.42 & $\begin{array}{l}29 . \\
0\end{array}$ & 0.67 & 2 \\
\hline Etna & ETN & Trachybasalt & $\begin{array}{l}47.0 \\
3\end{array}$ & 1.61 & $\begin{array}{l}16.2 \\
8\end{array}$ & 10.13 & 0.20 & 5.17 & $\begin{array}{l}10.4 \\
7\end{array}$ & 3.75 & 1.94 & 0.59 & 97.17 & 0.50 & $\begin{array}{l}31 . \\
1\end{array}$ & 0.48 & 3 \\
\hline Vesuvius & Ves_Gt & Phonotephrite & $\begin{array}{l}49.7 \\
0\end{array}$ & 0.84 & $\begin{array}{l}16.5 \\
7\end{array}$ & 7.27 & 0.13 & 5.15 & $\begin{array}{l}10.3 \\
0\end{array}$ & 2.73 & 6.57 & 0.73 & 99.99 & 0.53 & $\begin{array}{l}31 . \\
1\end{array}$ & 0.55 & 3 \\
\hline $\begin{array}{l}\text { Nyiragon } \\
\text { go }\end{array}$ & NYI & Foidite & $\begin{array}{l}41.0 \\
7\end{array}$ & 2.75 & $\begin{array}{l}14.9 \\
7\end{array}$ & 11.99 & 0.32 & 3.72 & $\begin{array}{l}10.3 \\
9\end{array}$ & 6.89 & 5.61 & 1.22 & 98.93 & 0.73 & $\begin{array}{l}35 . \\
9\end{array}$ & 0.25 & 3 \\
\hline
\end{tabular}




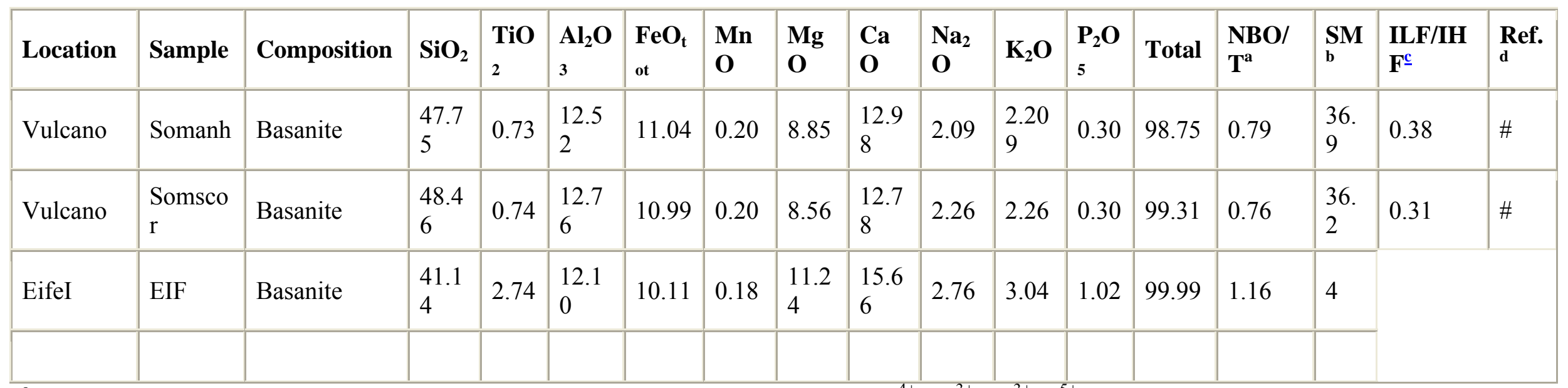

${ }^{\mathrm{a}} \mathrm{NBO} / \mathrm{T}$, number of non-bridging oxygens per tetrahedrally coordinated cations $\left(\mathrm{Si}^{4+}, \mathrm{Al}^{3+}, \mathrm{Fe}^{3+}, \mathrm{P}^{5+}\right)$. Reported values refer to dry compositions.

${ }^{\mathrm{b}} \mathrm{SM}$, number of structural modifiers $\left(\mathrm{Fe}^{2+}, \mathrm{Mn}^{2+}, \mathrm{Mg}^{2+}, \mathrm{Ca}^{2+}, \mathrm{Na}^{+}, \mathrm{K}^{+}\right)$.

${ }^{\mathrm{c}} I_{\mathrm{LF}} / I_{\mathrm{HF}}$ values represent the height of the LF band $\left(\sim 490 \mathrm{~cm}^{-1}\right)$ normalised to the height of HF band $\left(\sim 960 \mathrm{~cm}^{-1}\right)$.

${ }^{\mathrm{d}}$ References: \#, this study; 1, Robert et al. (2008); 2, Giordano et al. (2006); 3, Giordano and Dingwell (2003); 4, Giordano et al. (2007); 5, Scaillet and Evans (1999); the major element compositions are measured using the SX 100 CAMECA electron microprobe (CAMPARIS-ParisFrance). Total water content in glasses has been determined by Karl Fisher Titration (KFT) with a relative deviation of 5\%, except for LIP glasses which was analysed using hydrogen manometry. 

Table 1b. : Compositions, iron oxidation states, synthesis conditions and intensity ratios of measured Raman bands related to vibration of alumino silicate network (LF; HF) for anhydrous basaltic glasses with variable iron oxidation state.

\begin{tabular}{|c|c|c|c|c|c|c|c|c|c|c|c|c|c|c|c|c|c|c|c|c|}
\hline Location & Sample & Composition & $\mathrm{SiO}_{2}$ & $\mathrm{TiO}_{2}$ & $\mathrm{Al}_{2} \mathrm{O}_{3}$ & $\mathrm{FeO}_{\text {tot }}$ & $\mathrm{MnO}$ & $\mathrm{MgO}$ & $\mathrm{CaO}$ & $\mathrm{Na}_{2} \mathrm{O}$ & $\mathrm{K}_{2} \mathrm{O}$ & $\mathrm{P}_{2} \mathrm{O}_{5}$ & Total & $\mathrm{NBO} / \mathrm{T}^{\mathrm{a}}$ & $\mathrm{SM}^{\mathrm{b}}$ & $\mathrm{Fe}^{3+} / \mathrm{Fe}_{\mathrm{T}}{ }^{\mathrm{e}}$ & $\mathrm{ILF} / \mathrm{IHF}^{\mathrm{c}}$ & $\begin{array}{l}\mathrm{T} \\
\left({ }^{\circ} \mathrm{C}\right)\end{array}$ & $\begin{array}{l}\mathrm{P} \\
\text { (bar) }\end{array}$ & Ref. $^{d}$ \\
\hline Etna & $\begin{array}{l}\text { Et83- } \\
\text { Illbasal }\end{array}$ & Basalt & 48.33 & 1.78 & 17.62 & 9.62 & 0.19 & 5.42 & 10.31 & 3.80 & 1.88 & 0.59 & 99.54 & 0.59 & 34.2 & 0.10 & 0.59 & 1260 & 1 & $\begin{array}{l}\text { Bonnin- } \\
\text { Mosbah } \\
\text { et al. } \\
(2002)\end{array}$ \\
\hline Etna & $\begin{array}{l}\text { Et83- } \\
\text { XXII }\end{array}$ & Basalt & 47.66 & 1.74 & 18.35 & 9.89 & 0.20 & 5.41 & 10.08 & 3.69 & 1.79 & 0.59 & 99.40 & 0.51 & 33.2 & 0.22 & 0.63 & 1300 & 1 & $\begin{array}{l}\text { Bonnin- } \\
\text { Mosbah } \\
\text { et al. } \\
(2002)\end{array}$ \\
\hline Etna & $\begin{array}{l}\text { Et83- } \\
\mathrm{XX}\end{array}$ & Basalt & 47.74 & 1.76 & 17.89 & 9.87 & 0.18 & 5.48 & 10.15 & 3.74 & 1.83 & 0.59 & 99.23 & 0.49 & 32.6 & 0.32 & 0.62 & 1300 & 1 & $\begin{array}{l}\text { Bonnin- } \\
\text { Mosbah } \\
\text { et al. } \\
\text { (2002) }\end{array}$ \\
\hline Etna & $\begin{array}{l}\text { Et83- } \\
\text { VI11 }\end{array}$ & Basalt & 47.67 & 1.79 & 16.88 & 10.34 & 0.22 & 5.43 & 10.11 & 3.70 & 1.86 & 0.59 & 98.59 & 0.50 & 32.5 & 0.37 & 0.65 & 1300 & 1 & $\begin{array}{l}\text { Bonnin- } \\
\text { Mosbah } \\
\text { et al. } \\
\text { (2002) }\end{array}$ \\
\hline Etna & Et83-X & Basalt & 46.70 & 1.84 & 17.69 & 10.12 & 0.16 & 5.27 & 10.10 & 3.75 & 1.86 & 0.59 & 98.08 & 0.43 & 31.4 & 0.48 & 0.63 & 1300 & 1 & $\begin{array}{l}\text { Bonnin- } \\
\text { Mosbah } \\
\text { et al. } \\
(2002)\end{array}$ \\
\hline Stromboli & Str85-III & Basalt & 51.03 & 0.93 & 18.42 & 7.06 & 0.18 & 5.70 & 10.94 & 2.68 & 2.36 & 0.58 & 99.88 & 0.53 & 32.7 & 0.05 & 0.58 & 1270 & 1 & $\begin{array}{l}\text { Bonnin- } \\
\text { Mosbah } \\
\text { et al. } \\
(2002)\end{array}$ \\
\hline Stromboli & $\begin{array}{l}\text { Str85- } \\
\text { XVI }\end{array}$ & Basalt & 50.18 & 0.96 & 17.96 & 7.42 & 0.16 & 5.85 & 10.65 & 2.58 & 2.20 & 0.58 & 98.54 & 0.45 & 31.1 & 0.33 & 0.63 & 1300 & 1 & $\begin{array}{l}\text { Bonnin- } \\
\text { Mosbah } \\
\text { et al. } \\
(2002)\end{array}$ \\
\hline Stromboli & $\begin{array}{l}\text { Str85- } \\
\text { XII }\end{array}$ & Basalt & 51.12 & 0.92 & 17.82 & 7.76 & 0.16 & 5.72 & 10.66 & 2.60 & 2.24 & 0.58 & 99.58 & 0.41 & 30.0 & 0.46 & 0.69 & 1300 & 1 & $\begin{array}{l}\text { Bonnin- } \\
\text { Mosbah } \\
\text { et al. } \\
\text { (2002) }\end{array}$ \\
\hline
\end{tabular}




\begin{tabular}{|c|c|c|c|c|c|c|c|c|c|c|c|c|c|c|c|c|c|c|c|c|}
\hline Location & Sample & Composition & $\mathrm{SiO}_{2}$ & $\mathrm{TiO}_{2}$ & $\mathrm{Al}_{2} \mathrm{O}_{3}$ & $\mathrm{FeO}_{\text {tot }}$ & $\mathrm{MnO}$ & $\mathrm{MgO}$ & $\mathrm{CaO}$ & $\mathrm{Na}_{2} \mathrm{O}$ & $\mathrm{K}_{2} \mathrm{O}$ & $\mathrm{P}_{2} \mathrm{O}_{5}$ & Total & $\mathrm{NBO} / \mathrm{T}^{\mathrm{a}}$ & $\mathrm{SM}^{\mathrm{b}}$ & $\mathrm{Fe}^{3+} / \mathrm{Fe}_{\mathrm{T}}{ }^{\mathrm{e}}$ & ILF/IHF & \begin{tabular}{|l}
$\mathrm{T}$ \\
$\left({ }^{\circ} \mathrm{C}\right)$
\end{tabular} & \begin{tabular}{|l}
$\mathrm{P}$ \\
(bar)
\end{tabular} & Ref. $^{d}$ \\
\hline Stromboli & Str85-I & Basalt & 49.42 & 0.88 & 16.95 & 7.93 & 0.165 & 6.19 & 10.82 & 2.58 & 2.19 & 0.58 & 97.71 & 0.35 & 28.9 & 0.87 & & & & \\
\hline
\end{tabular}

a, b, c, d :see Table 1a.

${ }^{\mathrm{e}} \mathrm{FeO}$ and $\mathrm{Fe}_{2} \mathrm{O}_{3}$ are determined on bulk rocks by volumetric titration and atomic absorption methods, respectively with an error $(1 \sigma)$ of $0.5 \%$ and $1 \%$.

Table 1c. : Compositions (EPMA), water contents (KFT), synthesis conditions and intensity ratios of measured Raman bands related to vibration of alumino silicate network (LF; HF) for hydrous glasses.

\begin{tabular}{|c|c|c|c|c|c|c|c|c|c|c|c|c|c|c|c|c|c|c|c|c|}
\hline Location & Sample & Composition & $\mathrm{SiO}_{2}$ & $\mathrm{TiO}_{2}$ & $\mathrm{Al}_{2} \mathbf{O}_{3}$ & $\mathrm{FeO}_{\text {tot }}$ & MnO & MgO & $\mathrm{CaO}$ & $\mathrm{Na}_{2} \mathrm{O}$ & $\mathbf{K}_{2} \mathbf{O}$ & $\mathbf{P}_{2} \mathbf{O}_{5}$ & Total & $\mathrm{NBO} / \mathrm{T}^{\mathrm{a}}$ & $\mathbf{S M}^{\mathbf{b}}$ & $\mathrm{H}_{2} \mathrm{O}(\mathrm{wt} \%)$ & $I_{\mathrm{LF}} / I_{\mathrm{HF}}{ }^{\mathrm{c}}$ & $T\left({ }^{\circ} \mathbf{C}\right)$ & $P$ (bar) & Ref. ${ }^{d}$ \\
\hline Etna & Etna 4.95 & Basalt & 49.22 & 1.77 & 16.39 & 9.01 & 0.14 & 6.74 & 10.76 & 3.73 & 2.22 & nd & 100.00 & 0.52 & 27.3 & 4.95 & 0.77 & 1200 & 2138 & 7 \\
\hline Etna & EtII-1 & Basalt & 48.74 & 8.74 & 16.93 & 6.08 & 0.18 & 5.51 & 10.43 & 3.83 & 1.97 & 0.63 & 96.04 & 0.48 & 27.1 & 3.04 & 0.81 & 1200 & 2000 & 8 \\
\hline Etna & EtIII-2a & Basalt & 47.48 & 1.61 & 16.06 & 9.32 & 0.17 & 5.99 & 10.19 & 3.24 & 1.87 & 0.61 & 96.54 & 0.51 & 27.1 & 2.41 & 0.61 & 1200 & 1500 & 8 \\
\hline Etna & EtIII-1a & Basalt & 47.42 & 1.67 & 15.76 & 10.41 & 0.17 & 6.02 & 10.11 & 3.20 & 1.82 & 0.60 & 97.18 & 0.52 & 27.1 & 1.75 & 0.57 & 1200 & 1500 & 8 \\
\hline Etna & EtIII-0.5a & Basalt & 48.29 & 1.70 & 16.32 & 9.08 & 0.17 & 6.08 & 10.13 & 3.38 & 1.96 & 0.62 & 97.73 & 0.51 & 27.1 & 1.27 & 0.58 & 1200 & 1500 & 8 \\
\hline Etna & EtII-6 & Basalt & 47.79 & 1.74 & 16.91 & 8.80 & 0.16 & 5.45 & 10.2 & 3.83 & 1.96 & 0.62 & 97.46 & 0.48 & 27.1 & 1.19 & 0.59 & 1200 & 2000 & 8 \\
\hline Etna & Etna 0.80 & Basalt & 47.96 & 1.62 & 16.64 & 9.80 & 0.22 & 6.20 & 10.38 & 3.47 & 1.85 & 0.13 & 98.27 & 0.49 & 27.1 & 0.80 & 0.55 & 1200 & 500 & \# \\
\hline Etna & Etna 0.40 & Basalt & 48.74 & 1.83 & 15.82 & 9.64 & 0.18 & 6.10 & 10.18 & 3.50 & 1.89 & 0.13 & 98.01 & 0.49 & 27.1 & 0.40 & 0.54 & 1200 & 500 & $\#$ \\
\hline Vesuvius & Run1\#1 & Tephrite & 50.75 & 1.01 & 14.44 & 6.20 & 0.17 & 6.70 & 12.54 & 2.07 & 6.10 & nd & 100.00 & 0.63 & 28.3 & 5.30 & 0.70 & 1200 & 2059 & 7 \\
\hline Vesuvius & Run7\#1 & Tephrite & 49.39 & 0.98 & 14.49 & 7.37 & 0.12 & 7.31 & 12.61 & 1.93 & 5.80 & nd & 100.00 & 0.66 & 31.0 & 3.50 & 0.58 & 1200 & 1006 & 7 \\
\hline Vesuvius & Run8\#1 & Tephrite & 49.42 & 0.99 & 14.27 & 7.55 & 0.12 & 6.71 & 12.75 & 1.96 & 6.21 & nd & 100.00 & 0.66 & 32.2 & 2.10 & 0.53 & 1200 & 517 & 7 \\
\hline Sommata & Som 4.95 & Basanite & 46.78 & 0.78 & 12.15 & 9.65 & 0.21 & 8.12 & 12.05 & 1.94 & 2.02 & 0.30 & 94.01 & 0.76 & 30.2 & 4.95 & 0.54 & 1200 & 2000 & $\#$ \\
\hline Sommata & Som 3.90 & Basanite & 47.23 & 0.69 & 12.32 & 9.75 & 0.19 & 8.40 & 12.48 & 2.22 & 2.09 & 0.30 & 95.67 & 0.76 & 31.8 & 3.90 & 0.48 & 1200 & 1000 & \# \\
\hline Sommata & Som 3.30 & Basanite & 48.09 & 0.74 & 12.45 & 9.81 & 0.19 & 8.35 & 12.56 & 2.23 & 2.18 & 0.30 & 96.90 & 0.75 & 32.1 & 3.30 & 0.44 & 1200 & 1000 & \# \\
\hline
\end{tabular}




\begin{tabular}{|c|c|c|c|c|c|c|c|c|c|c|c|c|c|c|c|c|c|c|c|c|}
\hline Location & Sample & Composition & $\mathrm{SiO}_{2}$ & $\mathrm{TiO}_{2}$ & $\mathrm{Al}_{2} \mathbf{O}_{3}$ & $\mathrm{FeO}_{\text {tot }}$ & MnO & MgO & $\mathrm{CaO}$ & $\mathrm{Na}_{2} \mathrm{O}$ & $\mathrm{K}_{2} \mathrm{O}$ & $\mathbf{P}_{2} \mathbf{O}_{5}$ & Total & $\mathrm{NBO} / \mathrm{T}^{\mathrm{a}}$ & $\mathbf{S M}^{\mathrm{b}}$ & $\mathrm{H}_{2} \mathrm{O}(\mathrm{wt} \%)$ & $\boldsymbol{I}_{\mathrm{LF}} / \boldsymbol{I}_{\mathrm{HF}}^{\mathrm{c}}$ & $T\left({ }^{\circ} \mathrm{C}\right)$ & $P$ (bar) & Ref. $^{d}$ \\
\hline Sommata & Som 2.45 & Basanite & 48.36 & 0.75 & 12.54 & 9.71 & 0.20 & 8.45 & 12.62 & 2.31 & $2 . .20$ & 0.31 & 97.45 & 0.75 & 33.1 & 2.45 & 0.45 & 1200 & 1000 & \# \\
\hline Sommata & Som 1.53 & Basanite & 48.51 & 0.73 & $12 . .54$ & 9.91 & 0.26 & 8.36 & 12.38 & 2.44 & 2.12 & 0.27 & 97.52 & 0.74 & 33.9 & 1.53 & 0.42 & 1200 & 500 & \# \\
\hline Sommata & Som 1.43 & Basanite & 48.5 & 0.75 & 12.63 & 9.92 & 0.21 & 8.60 & 12.91 & 2.35 & 2.19 & 0.29 & 98.35 & 0.77 & 34.6 & 1.43 & 0.40 & 1200 & 500 & \# \\
\hline Sommata & Som 0.79 & Basanite & 49.13 & 0.82 & 12.92 & 9.97 & 0.19 & 8.53 & 12.63 & 2.20 & 2.16 & 0.36 & 98.91 & 0.74 & 34.6 & 0.79 & 0.37 & 1200 & 500 & \# \\
\hline Vesuvius & Pompeï & Phonolite & 56.09 & 0.19 & 22.02 & 2.26 & nd & 0.18 & 2.80 & 6.22 & 10.25 & nd & 100.00 & 0.08 & 15.1 & 6.80 & 1.93 & 1200 & 2000 & 9 \\
\hline Vesuvius & Pompeï & Phonolite & 56.09 & 0.19 & 22.02 & 2.26 & nd & 0.18 & 2.80 & 6.22 & 10.25 & nd & 100.00 & 0.08 & 15.1 & 4.43 & 1.92 & 1200 & 2000 & 9 \\
\hline Vesuvius & Pompeï & Phonolite & 56.09 & 0.19 & 22.02 & 2.26 & nd & 0.18 & 2.80 & 6.22 & 10.25 & nd & 100.00 & 0.08 & 15.1 & 2.38 & 1.68 & 1200 & 2000 & 9 \\
\hline Vesuvius & Pollena & Phonolite & 51.36 & 0.48 & 21.63 & 4.54 & nd & 0.74 & 5.90 & 5.92 & 9.42 & nd & 100.00 & 0.19 & 18.9 & 6.70 & 1.51 & 1200 & 2000 & 9 \\
\hline Vesuvius & Pollena & Phonolite & 51.36 & 0.48 & 21.63 & 4.54 & nd & 0.74 & 5.90 & 5.92 & 9.42 & nd & 100.00 & 0.19 & 20.3 & 4.67 & 1.44 & 1200 & 2000 & 9 \\
\hline Vesuvius & Pollena & Phonolite & 51.36 & 0.48 & 21.63 & 4.54 & nd & 0.74 & 5.90 & 5.92 & 9.42 & nd & 100.00 & 0.19 & 21.9 & 2.52 & 1.30 & 1200 & 2000 & 9 \\
\hline Turkey & GD & Metal. rhyolite & 76.51 & 0.03 & 12.56 & 0.70 & 0.07 & 0.01 & 0.25 & 4.47 & 4.24 & 0.00 & 98.84 & 0.01 & 6.6 & 7.00 & 4.18 & 1000 & 2500 & 10 \\
\hline Mexico & M77 & Metal. rhyolite & 76.14 & 0.13 & 12.91 & 0.93 & 0.03 & 0.12 & 0.92 & 2.98 & 5.81 & 0.01 & 99.98 & 0.01 & 7.8 & 3.50 & 3.34 & $?$ & $<5$ & 11 \\
\hline Lipari & LIP & Metal. rhyolite & 74.71 & 0.09 & 13.35 & 1.57 & 0.08 & 0.04 & 0.77 & 3.89 & 5.48 & 0.03 & 100.01 & 0.02 & 9.4 & 0.52 & 2.64 & ? & & \\
\hline
\end{tabular}

